University of Wollongong

Research Online

Faculty of Engineering and Information

Faculty of Engineering and Information

Sciences - Papers: Part B

Sciences

2017

\title{
Behaviour of concrete-encased concrete-filled FRP tube (CCFT) columns under axial compression
}

Weiqiang Wang

University of Technology Sydney, ww674@uowmail.edu.au

M Neaz Sheikh

University of Wollongong, msheikh@uow.edu.au

Muhammad N. S Hadi

University of Wollongong, mhadi@uow.edu.au

Danying Gao

Zhengzhou University

Gang Chen

Zhengzhou University

Follow this and additional works at: https://ro.uow.edu.au/eispapers1

Part of the Engineering Commons, and the Science and Technology Studies Commons

Research Online is the open access institutional repository for the University of Wollongong. For further information contact the UOW Library: research-pubs@uow.edu.au 


\title{
Behaviour of concrete-encased concrete-filled FRP tube (CCFT) columns under axial compression
}

\author{
Abstract \\ A new composite column named concrete-encased concrete-filled fibre reinforced polymer tube (CCFT) \\ column has been proposed in this study. This composite column consists of an inner concrete-filled fibre \\ reinforced polymer (FRP) tube, outer concrete confined with polymer grid, and concrete cover. In this \\ study, a total of 16 concrete stub columns were cast and tested under axial compression. Columns were \\ divided into eight groups, which included one group of plain concrete columns, two groups of FRP \\ confined concrete columns, and five groups of CCFT columns. For FRP confined concrete columns, one \\ layer and two layers of carbon FRP (CFRP) sheet were wrapped, respectively. For CCFT columns, glass \\ FRP (GFRP) tube was used to confine the inner concrete, and polymer grid was used to confine the outer \\ concrete. The test results show that considerable increase in strength and ductility can be obtained for \\ CCFT columns. An analytical model has been developed to predict the axial compressive behaviour of \\ CCFT columns. The analytical results have been found to be in good agreement with the experimental \\ results. Based on the analytical model, the influences of different parameters on the axial compressive \\ behaviour of CCFT columns have been investigated through parametric analyses.

\section{Disciplines} \\ Engineering | Science and Technology Studies

\section{Publication Details} \\ Wang, W., Sheikh, M. Neaz., Hadi, M. N. S., Gao, D. \& Chen, G. (2017). Behaviour of concrete-encased \\ concrete-filled FRP tube (CCFT) columns under axial compression. Engineering Structures, 147 256-268.
}


Behaviour of concrete-encased concrete-filled FRP tube (CCFT) columns under axial compression

Weiqiang Wang ${ }^{\mathrm{a}}$, M. Neaz Sheikh ${ }^{\mathrm{b}}$, Muhammad N. S. Hadi ${ }^{\mathrm{b}, *}$, Danying Gao ${ }^{\mathrm{c}}$, Gang Chen ${ }^{\mathrm{c}}$

${ }^{a}$ Centre for Built Infrastructure Research, School of Civil and Environmental Engineering, University of Technology Sydney, NSW 2007, Australia

${ }^{\mathrm{b}}$ School of Civil, Mining and Environmental Engineering, University of Wollongong, NSW 2522, Australia

${ }^{\mathrm{c}}$ Research Centre of New Style Building Material and Structure, Zhengzhou University, Zhengzhou, Henan 450002, China

Correspondence:

Muhammad N. S. Hadi

24 School of Civil, Mining \& Environmental Engineering

25 University of Wollongong, Australia

26 E-mail:mhadi@uow.edu.au

27 Telephone: + 61242214762

28 Facsimiles: + 61242213238

29

* Corresponding author 


\title{
Behaviour of concrete-encased concrete-filled FRP tube (CCFT) columns under axial compression
}

\begin{abstract}
A new composite column named concrete-encased concrete-filled fibre reinforced polymer tube (CCFT) column has been proposed in this study. This composite column consists of an inner concrete-filled fibre reinforced polymer (FRP) tube, outer concrete confined with polymer grid, and concrete cover. In this study, a total of 16 concrete stub columns were cast and tested under axial compression. Columns were divided into eight groups, which included one group of plain concrete columns, two groups of FRP confined concrete columns, and five groups of CCFT columns. For FRP confined concrete columns, one layer and two layers of carbon FRP (CFRP) sheet were wrapped, respectively. For CCFT columns, glass FRP (GFRP) tube was used to confine the inner concrete, and polymer grid was used to confine the outer concrete. The test results show that considerable increase in strength and ductility can be obtained for CCFT columns. An analytical model has been developed to predict the axial compressive behaviour of CCFT columns. The analytical results have been found to be in good agreement with the experimental results. Based on the analytical model, the influences of different parameters on the axial compressive behaviour of CCFT columns have been investigated through parametric analyses.
\end{abstract}

Keywords: CCFT columns; Axial compression; Analytical model; FRP tube; CFRP; GFRP. 


\section{1. Introduction}

In the past two decades, a significant number of studies were carried out on the use of fibre reinforced polymer (FRP) composites in civil engineering construction. One major application is the use of FRP jacket for strengthening existing concrete columns [1]. Many studies reported the effectiveness of FRP jacket to enhance both the strength and ductility of concrete columns by providing confinement to the concrete under concentric or eccentric compressive loadings [2, 3]. More recently, several studies were focussed on the use of FRP composites for the construction of new concrete structures, such as concrete-filled FRP tubes (CFFTs) and FRP bars reinforced concrete (RC) members [4-23].

The CFFTs was first proposed by Mirmiran et al. [4]. In CFFTs, the FRP tube acts as stay-in-place formwork and provides lateral confinement to concrete. At the same time, the infilled concrete prevents the FRP tube from local buckling. A significant number of studies demonstrated the ability of CFFTs to develop considerable strength, stiffness and ductility, making FRP tube an attractive alternative to steel tube and steel bars [5-10]. With the increasing popularity of the construction of CFFTs column in China, a national technical code was developed for the rational design of CFFTs [11]. Despite many advantages of CFFTs, few disadvantages still exist, which include weak fire resistance [12], sudden failure, and difficulty to create moment resisting connection to other structural components. Several studies have been conducted to address the above-mentioned disadvantages and suggested that these disadvantages can be reasonably avoided or alleviated [13-15]. Until now, CFFTs have been adopted for the construction of bridge columns and piles [11].

The behaviour of concrete members internally reinforced with FRP bars was investigated in recent years [16]. The use of FRP bars is particularly attractive for concrete structures under harsh environments where corrosion of steel bars is a major concern. Many studies reported that FRP bars could be successfully used to replace traditional steel bars in RC beams $[17,18]$. On the other hand, the use of FRP bars as longitudinal reinforcement has not been considered a suitable option for RC compression members and not yet covered by ACI 440.1R-06 [16]. The main reasons for not using the FRP bars in concrete columns are: (a) the strength and stiffness of FRP bars in compression are 
less than those in tension [19]; (b) a tensile strength reduction of more than $40 \%$ can occur for transverse FRP bars with bends compared to the tensile strength of straight FRP bars due to fibre bending and stress concentration [20]; and (c) the longitudinal FRP bars are vulnerable to local bucking [21]. More recently, several studies investigated the behaviour of FRP bars reinforced concrete columns under compression [21-23], and these studies suggested that FRP bars can also be used for the reinforcement of concrete columns if sufficient FRP bars are provided.

In this study, a new composite column named concrete-encased concrete-filled FRP tube (CCFT) column has been proposed. This composite column consists of an inner concrete-filled FRP tube and an outer concrete component, as shown in Fig. 1. The outer concrete component can be divided into two parts: outer confined concrete and concrete cover. Polymer grid has been used to provide confinement to outer confined concrete in this study [24, 25]. Longitudinal reinforcement (e.g., FRP bars) can also be used for the outer concrete in order to improve the performance of CCFT column. The CCFT column is expected to possess several advantages. First, the fire resistance of CCFT column can be improved because of the presence of outer concrete component. Second, the spalling of concrete cover can be used as a suitable indication before sudden failure. Third, the moment resisting connection with the concrete beams can be constructed due to the presence of outer concrete component [26]. During the construction, the inner concrete-filled FRP tube can be constructed first to carry the construction load before the construction of the outer concrete component. Moreover, when compared to FRP bars reinforced concrete columns, the FRP tube can provide higher confinement to the inner concrete than FRP bars. Consequently, the cross-sectional dimension of the CCFT column can be reduced if the same design load is required. Despite many advantages, some disadvantages still exist. For example, the construction of the proposed CCFT column may be more challenging than that of CFFTs and FRP bars reinforced concrete columns, which is mainly due to the complexity of the column type.

In order to have an in-depth understanding of the axial compressive behaviour of the proposed CCFT column, an experimental program was carried out at the High Bay Civil Engineering Laboratory of the University of Wollongong, Australia. The failure modes and axial load-axial deformation 
behaviour have been investigated. Afterwards, an analytical model has been developed to predict the performance of CCFT columns under axial compression. The analytical model has been fully validated with experimental results. Finally, parametric analyses have been carried out to investigate the influences of different parameters on the axial compressive behaviour of CCFT columns.

\section{Experimental program}

\subsection{Design of experiment}

A total of 16 concrete stub columns with $150 \mathrm{~mm}$ in diameter and $300 \mathrm{~mm}$ in height were cast and tested under axial compression. The concrete columns were divided into eight groups with two identical columns in each group. One group of plain concrete columns, two groups of FRP confined concrete columns, and five groups of concrete-encased concrete-filled FRP tube (CCFT) columns were tested in this study. Plain concrete columns and FRP confined concrete columns were used mainly for comparison purpose to understand the behaviour of CCFT columns. One layer and two layers of carbon FRP (CFRP) sheet were wrapped for FRP confined concrete columns, respectively. For CCFT columns, Glass FRP (GFRP) tubes with $6 \mathrm{~mm}$ thick and $77 \mathrm{~mm}$ inner diameter were used in this study. Polymer grid was chosen as the confinement of the outer concrete. Two types of polymer grid were used (Type A and Type B). The polymer grid was formed into tubular shape (e.g., tubular polymer grid) to provide confinement to the outer concrete. The diameter of the tubular grid was $133 \mathrm{~mm}$. The clear concrete cover was $20 \mathrm{~mm}$ at the top and bottom of the column. Details of the test matrix are presented in Table 1.

The labelling of concrete columns has been carried out as: (a) "P" is used to identify plain concrete columns; (b) "FC" represents FRP confined concrete columns, and the number afterwards indicates number of CFRP layers; (c) "CCFT" indicates concrete-encased concrete-filled FRP tube columns; (d) "O" indicates no confinement was provided to the outer concrete of CCFT columns; (e) "A" and "B" indicate types of polymer grid used for the confinement of the outer concrete of CCFT columns, and the number before indicates the number of polymer grid layers. For instance, column FC-1 indicates 
FRP confined concrete columns wrapped with one layer of CFRP sheet. Column CCFT-1A indicates

137 CCFT columns for which the outer concrete was confined with one layer of Type A polymer grid.

\subsection{Materials}

140 The GFRP tubes used in this study were manufactured by Wagners CFT [27]. The mechanical 141 properties of GFRP tubes provided by the manufacturers are listed in Table 2. Type A polymer grid was square in shape $(36 \times 36 \mathrm{~mm})$ and was manufactured from polypropylene by Polyfabrics Australia Pty Ltd [28]. Type B polymer grid was rectangular in shape $(36 \times 24 \mathrm{~mm})$ and was manufactured from high modulus polyester fibres by Maccaferri Australia [29]. It was noted that the tubular polymer grid was overlapped at an approximate length of $70 \mathrm{~mm}$ to ensure that the polymer grid would not be loosened or slid and to provide uniform confinement to the outer concrete. The carbon FRP (CFRP) sheet was manufactured by Hitech Composites Co., Ltd [30]. The nominal thickness and width of each layer of CFRP sheet were $0.167 \mathrm{~mm}$ and $100 \mathrm{~mm}$, respectively. According to the properties provided by the manufacturers, the ultimate tensile strength of CFRP sheet was $3400 \mathrm{MPa}$ with a tensile rupture strain of $0.017 \mathrm{~mm} / \mathrm{mm}$. Normal strength concrete with a design compressive strength of $32 \mathrm{MPa}$ was used for casting the concrete columns. The mix design of the concrete is listed in Table 3. The Pozz80 water reducer and the MA940 air entrainer were supplied by BASF Australia [31].

\subsection{Preparation of concrete columns}

For FRP confined concrete columns, the CFRP sheet was wrapped onto the columns manually using a wet lay-up method. A mixture of epoxy resin and hardener at a ratio of 5:1 was used as the adhesive. Before the wrapping of the first layer of CFRP, the adhesive was spread onto the surface of the column. After the first layer of CFRP was wrapped, the adhesive was spread onto the first layer of CFRP and the second layer was continuously wrapped. An overlap of $100 \mathrm{~mm}$ was maintained to prevent the premature debonding of CFRP. The epoxy resin was then left to cure for two weeks. 
162 For CCFT columns, GFRP tube and tubular polymer grid were placed into the mould before casting 163 the concrete, as show in Fig. 2. Strain gauges were longitudinally and transversely attached onto the 164 mid-height of GFRP tubes to investigate the actual strain distributions. In order to ensure a $20 \mathrm{~mm}$ concrete cover at the top and bottom of the columns, three tiny holes were drilled into the timber base as well as at the bottom of GFRP tubes. The holes were $10 \mathrm{~mm}$ in depth. Afterwards, three $40 \mathrm{~mm}$ long thin steel wires were inserted into the holes to support the GFRP tubes and to maintain $20 \mathrm{~mm}$ concrete cover. The steel wires were removed from the concrete columns after the curing of concrete. To ensure that the GFRP tube was in the middle of the mould, four thin steel wires were aligned symmetrically around the top end of GFRP tube. The steel wires were removed after the casting of two thirds of the concrete. After the casting of concrete, all the concrete columns were kept wet during weekdays until the test date.

\subsection{Preliminary tests}

Concrete cylinders with $100 \mathrm{~mm}$ diameter and $200 \mathrm{~mm}$ height were tested for compressive strength at 28 days. The average compressive strength at 28 days was $35 \mathrm{MPa}$. The properties of CFRP sheet were determined by FRP coupon tests according to ASTM D7565 [32]. The average width of the coupons was $28.50 \mathrm{~mm}$ and the average maximum tensile force was $1200 \mathrm{~N} / \mathrm{mm}$. The recorded average ultimate tensile strain was $0.0172 \mathrm{~mm} / \mathrm{mm}$. testing, the tube was placed onto the loading plate to check for any misalignment between the tube end and the bottom loading plate. If a slight misalignment was observed, the tube end was slightly smoothed using a belt sander until the misalignment was removed. The test was conducted at a rate of $0.3 \mathrm{~mm} / \mathrm{min}$. The average axial compressive strength of GFRP tube was $493 \mathrm{MPa}$ with a corresponding axial strain of 0.0169 . Due to the limitations of the experimental setup, the hoop tensile properties of the GFRP tubes could not be experimentally obtained. 
Tensile properties of the polymer grid were determined by testing a single polymer grid strand using the Instron 8033 machine. Type A polymer grid strand was $2 \mathrm{~mm}$ in width and $1.5 \mathrm{~mm}$ in thickness, with a cross sectional area of $3 \times 10^{-6} \mathrm{~m}^{2}$. Type B polymer grid strand was $5 \mathrm{~mm}$ in width and $0.5 \mathrm{~mm}$ in thickness, with a cross sectional area of $2.5 \times 10^{-6} \mathrm{~m}^{2}$. Each end of the polymer grid strand was embedded in steel clamps. The displacement controlled test was carried out at a rate of $3 \mathrm{~mm} / \mathrm{min}$. More details can be found in Ref. [25]. Fig. 3 shows the tensile stress-tensile strain behaviour of polymer grid. A nonlinear tensile stress-tensile strain behaviour was observed for Type A polymer grid, while a linear elastic tensile stress-tensile strain behaviour was observed for Type B polymer grid. The average tensile strength was approximately $430 \mathrm{MPa}$ with an initial elastic modulus of 6.5 GPa for Type A polymer grid, while the average tensile strength was $464 \mathrm{MPa}$ with an elastic modulus of $5 \mathrm{GPa}$ for Type B polymer grid.

\subsection{Instrumentation and test procedure}

The Denison $5000 \mathrm{kN}$ testing machine in the High Bay laboratory at University of Wollongong was used for testing all the columns. Before testing, all the columns were capped at the top end with high strength plaster to ensure uniform load application. An additional layer of CFRP was wrapped at both ends of the columns to prevent premature damage at the ends. Adequate care was taken to ensure that the columns were placed at the center of the testing machine. Axial deformations were measured using two Linear Variable Differential Transducers (LVDTs), which were mounted at the corners between the loading plate and supporting steel plate. The deformation readings from the two LVDTs were averaged to obtain representative results. The load and deformation data were recorded using an electronic data-logger connected to a computer for every two seconds. The displacement controlled tests were carried out at a rate of $0.5 \mathrm{~mm} / \mathrm{min}$. 


\section{Experimental results and analysis}

212

213

\subsection{Failure modes}

Fig. 4 shows the representative failure modes of tested columns. FRP confined concrete columns (FC1, FC-2) failed in a brittle manner with rupture of CFRP sheet at the mid-height of columns, which was followed by crushing and spalling of the concrete (Fig. 4 (a)). For CCFT columns, the concrete cover began to spall off when the unconfined concrete compressive strength was approached. Nevertheless, the columns still experienced higher axial deformation after the spalling of concrete cover. All the CCFT columns finally failed due to the longitudinal rupture of GFRP tubes, which was accompanied by a loud noise. For Group CCFT-0 columns, most of the outer concrete spalled off (Fig. 4 (b)) since no confinement was provided to the outer concrete. For Groups CCFT-A and CCFT-B columns, the spalling of outer concrete was effectively controlled because of the confinement provided by the polymer grid (Fig. 4 (c)-(f)). The rupture of GFRP tubes resulted in a significant outward expansion of the CCFT columns. For Groups CCFT-1B and CCFT-2B columns, Type B polymer grid ruptured at the end of the test since the outward expansion of columns was severe. However, for Groups CCFT-1A and CCFT-2A columns, Type A polymer grid did not rupture at the end of the test, which was because the tensile rupture strain of Type A polymer grid was significantly higher than that of Type B polymer grid, as was evidenced in Fig. 3.

\subsection{Axial load-axial deformation behaviour}

Fig. 5 shows the axial load-axial deformation behaviour of Groups P(1), FC-1(1), FC-2(1), CCFT0(1), CCFT-1A(1), and CCFT-2A(1) columns. It is noted that the test results of two identical columns in each group were quite similar to each other; therefore, only the test result of one column in each group was displayed. The test results of all CCFT columns can be found in section 4 , in which all the test results were used to calibrate the accuracy of the proposed analytical model. It can be seen from Fig. 5 that all columns showed similar behaviour at the initial stage (i.e., axial load increased with the increase in axial deformation). Afterwards, the axial load of Group P columns decreased significantly and finally the column lost all the strength with a small deformation. Groups FC-1 and FC-2 columns 
experienced a typical linear increase in axial load with increase in the axial deformation and finally failed in a brittle manner with the rupture of CFRP sheet. The ultimate load and the corresponding axial deformations were highly dependent on the number of layers of CFRP sheet. For Group CCFT-0 columns, a considerable decrease in the axial load was observed after the first peak load (transition point between the initial ascending branch and the following descending branch), which is attributed to the spalling of outer concrete. For Groups CCFT-1A and CCFT-2A columns, no significant decrease in axial load was observed after the initial stage. It can be explained that the existence of polymer grid interrupted the consistency of the outer concrete, which may have adversely influenced the casting quality of the outer concrete and resulted in a strength loss. Afterwards, the axial loads of the CCFT columns was increased again because of the activation of confinement effect provided by GFRP tubes as well as the axial load carried by the GFRP tubes. Eventually, all the CCFT columns failed due to the rupture of the GFRP tubes. Fig. 6 shows the axial load-axial deformation diagram of Groups P(1), FC-1(1), FC-2(1), CCFT-0(1), CCFT-1B(1), and CCFT-2B(1) columns (all the test results of CCFT columns can be found in section 4). Similar behaviour can be observed.

It can be seen from Fig. 5 and Fig. 6 that after the spalling of concrete cover, a much higher ultimate deformation can be achieved. This is beneficial for the safe design of concrete columns: when the concrete cover began to spall off, more attention can be paid for evaluation the column to avoid catastrophic failure. Moreover, by using polymer grid as confinement of outer concrete, the load carrying capacity of CCFT columns was slightly increased. The increase of axial load was slightly higher if increased amount of polymer grid was applied. This insignificant axial load increase was attributed to the insufficient confinement provided by the polymer grid to the outer concrete, due to its large openings as well as its lower tensile elastic modulus and lower tensile strength. Therefore, polymer grid with smaller openings as well as higher tensile elastic modulus and higher tensile strength should be used. In addition, longitudinal reinforcement can be used to increase the axial load of outer concrete.

Table 4 summarizes the test results of all concrete columns. In this study, the ductility of the specimens was calculated as the ratio of the axial deformation at the ultimate load to the axial 
deformation at the first peak load [35-37]. For the specimens without a clear first peak load, axial deformation at the transition point between the first and second ascending parts was taken $[36,37]$.

267 The ductility of the columns has been calculated as:

$$
\mu=\frac{\delta_{u}}{\delta_{y}}
$$

268 where $\mu$ is the ductility of the column, $\delta_{u}$ is the axial deformation at the ultimate load, and $\delta_{y}$ is the axial deformation at the first peak load or the axial deformation at the transition point between the first and second ascending parts.

It can be seen from Table 4 that CCFT columns show significant increase in both the ultimate load and the ductility compared to those of plain concrete columns and FRP confined concrete columns. All CCFT columns possess much higher ultimate load and ductility than those of concrete columns confined with 1 layer of CFRP sheet. The ultimate loads of CCFT columns are slightly lower than those of columns confined with two layers of CFRP sheet. However, the ductility is significantly higher. By applying polymer grid, the ultimate load has been increased slightly, while the ductility has not been increased since the failure of concrete columns was dominated by the rupture of GFRP tubes.

\subsection{Interaction between different constituent materials}

In CCFT columns, the interactions include the composite action between the FRP tube and inner concrete, the constraint to the FRP tube by outer concrete, and the confinement to the outer concrete by the polymer grid. The interaction may have few stages. At the first stage, the transverse expansion of FRP tube is larger than that of concrete due to the Poisson's ratio effect (The Poisson's ratios are 0.27 and 0.2 for FRP tube and concrete, respectively). Therefore, the interaction between FRP tube and inner concrete does not exist, while the interaction between FRP tube and outer concrete exists. At this stage, the constraint to FRP tube by the outer concrete is not significant since all constituent materials are within the elastic state. At the second stage (especially after the unconfined concrete strength is reached), the transverse expansion of concrete becomes larger than that of FRP tube, and the confinement provided by the FRP tube to inner concrete is activated. Nevertheless, the interaction 
between FRP tube and outer concrete does not exist at this stage since the transverse expansion of outer concrete is more severe than that of FRP tube. The severe expansion of outer concrete is due to the insufficient confinement provided by the polymer grid. Therefore, the outer concrete cannot provide constraint to the FRP tube.

It has been reported that the transverse expansion of confined concrete depends heavily on the amount of confinement [38-41]. The concrete may exhibit a significant transverse expansion if less amount of confinement was provided (i.e. volume expansion). Otherwise, the transverse expansion can be less if the concrete is sufficiently confined (i.e. volume contraction). Therefore, if the inner concrete within the FRP tube is insufficiently confined and the outer concrete is sufficiently confined, the transverse expansion of FRP tube may be larger than that of outer concrete component. Under such circumstances, the interaction between FRP tube and inner concrete as well as the interaction between FRP tube and outer concrete component may both exist. As a result, the outward expansion of FRP tube can be effectively constrained by the outer confined concrete, which may delay the rupture of the FRP tube.

\section{Analytical model}

In order to better understand the axial compressive behaviour of CCFT columns, an analytical model has been developed in this section. Firstly, the stress-strain behaviours of different components (FRP tube, inner concrete, outer confined concrete, and cover concrete) of CCFT column have been described. Afterwards, an equation has been proposed to predict the load carrying capacity of CCFT columns. Finally, the analytical results have been compared with experimental results to validate the accuracy of the analytical model.

\subsection{Stress-strain behaviour of FRP tube}

313 Due to the existence of axial stiffness, the mechanical behaviour of FRP tube is more complicated than that of FRP sheet for which the axial stiffness can be neglected [42]. According to the mechanics 
of composite materials, the longitudinal compressive strength as well as transverse tensile strength of FRP tube can be determined as [43]:

$$
\begin{gathered}
\sigma_{l}=\frac{E_{f}}{1-v_{1} \nu_{2}} \varepsilon_{l}+\frac{\nu_{1} E_{f}}{1-v_{1} \nu_{2}} \varepsilon_{t} \\
\sigma_{t}=\frac{v_{2} E_{f, l}}{1-v_{1} v_{2}} \varepsilon_{l}+\frac{E_{f, l}}{1-v_{1} \nu_{2}} \varepsilon_{t}
\end{gathered}
$$

317 where $\sigma_{l}$ and $\sigma_{t}$ are the longitudinal compressive stress and transverse tensile stress of the FRP tube, Poisson's ratios, respectively.

For CCFT columns tested in this study, the GFRP tube is expected to fail if the longitudinal compressive strain of GFRP tube exceeded the longitudinal rupture strain $\varepsilon_{r u p}$ which was recorded by the strain gauges during the test. In Section 5.4, parametric analyses have been conducted to investigate the influences of filament winding angles on the axial compressive behaviour of CCFT columns. The failure modes of FRP tube can vary depending on the filament winding angles [5]. failure of FRP tubes with different filament winding angles. Various failure criteria were proposed to predict the failure of FRP tube [44-46]. Hinton et al. [47] reported that the Tsai-Wu failure criterion performed better than other failure criteria. Therefore, the Tsai-Wu failure criterion has been used to predict the failure of FRP tube with different filament winding angles in Section 5.4. The Tsai-Wu failure criterion can be expressed by Equation (4):

$$
\left(\frac{1}{f_{t, t}}-\frac{1}{f_{t, c}}\right) \sigma_{t}+\left(\frac{1}{f_{l, t}}-\frac{1}{f_{l, c}}\right) \sigma_{l}+\frac{1}{f_{t, t} f_{t, c}} \sigma_{t}^{2}+\frac{1}{f_{l, t} f_{l, c}} \sigma_{l}^{2}+\frac{\tau_{l}^{2}}{\tau^{2}}-\frac{1}{\sqrt{f_{l, t} f_{l, c} f_{t, t} f_{t, c}}} \sigma_{t} \sigma_{l}=1
$$
respectively; $f_{l, t}$ and $f_{t, t}$ are the longitudinal and transverse tensile strength, respectively; and $\tau$ is the shear strength of the FRP tube. 
4.2. Stress-strain behaviour of inner concrete

337 Many stress-strain models were proposed for FRP confined concrete [48]. During these models, the stress-strain model proposed by Lam and Teng [2] is used to model the inner concrete since this model has been proved to be one of the most accurate stress-strain models [48]. The stress-strain model proposed by Lam and Teng [2] is expressed by the following expressions (Equations (5-10)):

$$
\begin{array}{cc}
\sigma_{c}=E_{c} \varepsilon_{c}-\frac{\left(E_{c}-E_{2}\right)^{2}}{4 f_{o}} \varepsilon_{c}^{2} & \text { for } 0 \leq \varepsilon_{c} \leq \varepsilon_{t} \\
\sigma_{c}=f_{o}+E_{2} \varepsilon_{c} & \text { for } \varepsilon_{t} \leq \varepsilon_{c} \leq \varepsilon_{c u}
\end{array}
$$

341 where $\sigma_{c}$ and $\varepsilon_{c}$ are the axial stress and axial strain, respectively; $E_{c}$ is the elastic modulus of unconfined concrete; $E_{2}$ is the slope of the linear second portion of the stress-strain curve; $f_{o}$ is the intercept of the stress axis by the linear second portion; and $\varepsilon_{c u}$ is the ultimate axial strain of confined concrete. The parabolic first portion meets the linear second portion with a smooth transition at $\varepsilon_{t}$, which is given by

$$
\varepsilon_{t}=\frac{2 f_{o}}{\left(E_{c}-E_{2}\right)}
$$

346 The slope of the linear second portion $E_{2}$ is given by

$$
E_{2}=\frac{f_{c c}^{\prime}-f_{o}}{\varepsilon_{c u}}
$$

347 where $f_{c c}^{\prime}$ is the compressive strength of confined concrete. The value of $f_{o}$ is assumed to be the compressive strength of unconfined concrete $f_{c o}^{\prime}$. given by: 


$$
\begin{gathered}
\frac{f_{c c}^{\prime}}{f_{c o}^{\prime}}=1+3.3 \frac{f_{l u, a}}{f_{c o}^{\prime}} \\
\frac{\varepsilon_{c u}}{\varepsilon_{c o}}=1.75+12\left(\frac{f_{l u, a}}{f_{c o}^{\prime}}\right)\left(\frac{\varepsilon_{h, r u p}}{\varepsilon_{c o}}\right)^{0.45}
\end{gathered}
$$

351 where $f_{l u, a}$ is the actual lateral confining pressure; $\mathcal{E}_{c o}$ is the axial strain of unconfined concrete at 352 ultimate strength; and $\varepsilon_{h, r u p}$ is the actual tensile rupture strain of FRP tube.

4.3. Stress-strain behaviour of outer confined concrete and cover concrete

The strength of outer confined concrete is increased due to the confinement provided by the polymer grid. Currently, limited amount of research was carried out on the development of stress-strain models for the polymer grid confined concrete [25, 49]. Wang et al. [25] proposed a stress-strain model to predict the peak strength and peak strain of polymer grid confined concrete columns under axial compression. The model provides more accurate predictions of peak strength and peak strain than other available models [25]. However, the proposed stress-strain model cannot capture the full stressstrain behaviour of polymer grid confined concrete columns under axial compression. More recently, breakthrough have been made by Lim and Ozbakkaloglu [50, 51] on the full range stress-strain behaviour of actively and FRP confined concrete. New expressions were proposed for the stress-strain curve of actively confined concrete. By using the new expressions as base model, the stress-strain model of FRP confined concrete can be obtained, which is the so-called analysis-oriented model [50]. Wang et al. [25] tested 12 polymer grid confined concrete specimens under axial compression. It was observed that due to the insufficient amount of confinement, the stress-strain curve of polymer grid confined concrete experienced a significant drop after the peak stress, which was similar to that of lightly actively confined concrete [25]. On the other hand, the tensile strain at ultimate strength was about $13 \%$ for Type A polymer grid, while the tensile strain at ultimate strength was about $9 \%$ for Type B polymer grid. Also, the tensile elastic modulus was extremely low (6.5 GPa and $5 \mathrm{GPa}$ for Type A and Type B polymer grid, respectively). Due to the differences in the properties of the polymer grid used in this study and the traditional materials (steel and FRP), the confinement 
374 behaviour is believed to be different. However, no stress-strain models are available for concrete

375 confined with such types of materials. Therefore, the stress-strain model in Mander et al. [52] has 376 been used for a general prediction of the full stress-strain relationship of polymer grid confined 377 concrete. The stress-strain relationship for polymer grid confined concrete can be expressed by:

$$
f_{c}=\frac{x r f_{c c}^{\prime}}{r-1+x^{r}}
$$

378 in which

$$
\begin{gathered}
x=\frac{\mathcal{E}_{c}}{\mathcal{E}_{c c}^{\prime}} \\
r=\frac{E_{c}}{E_{c}-\frac{f_{c c}^{\prime}}{\mathcal{E}_{c c}^{\prime}}}
\end{gathered}
$$

379 where $f_{c c}^{\prime}$ is the peak compressive strength of polymer grid confined concrete; $\varepsilon_{c c}^{\prime}$ is the peak axial 380 compressive strain at the peak compressive strength of confined concrete $f_{c c}^{\prime} ; E_{c}$ is the elastic 381 modulus of the unconfined concrete, which can be calculated according to ACI 318-11 [53]:

$$
E_{c}=4730 \sqrt{f_{c c}^{\prime}}
$$

382 The peak strength and peak strain of polymer grid confined concrete can be calculated by [25]:

$$
\begin{aligned}
& \frac{f_{c c}^{\prime}}{f_{c o}^{\prime}}=1+0.0053 \lambda_{I} \\
& \frac{\varepsilon_{c c}^{\prime}}{\varepsilon_{c o}^{\prime}}=1+0.0073 \lambda_{I}
\end{aligned}
$$

383 in which

$$
\lambda_{1}=\frac{C_{j}}{\sqrt{f_{c o}^{\prime}}}
$$

384 The confinement modulus $C_{j}$ can be defined as [25]: 


$$
C_{j}=-\frac{2 k_{e} n A_{g}}{d_{g}\left(s_{g}+b_{g}\right)} E_{g}
$$

385 Where $n, b_{g}, s_{g}, A_{g}$ and $d_{g}$ are the number of polymer grid layers, width, spacing between 386 transverse polymer grid, cross sectional area of the polymer grid, and the diameter of the polymer grid, 387 respectively. $k_{e}$ is the confinement effective coefficient which was firstly proposed by Sheikh and Uzumeri [54], which can be expressed as:

$$
k_{e}=\left(1-\frac{s_{g}}{2 d_{g}}\right)^{2}
$$

389

390

391

392

The stress-strain relationship of cover concrete is described using Mander's model [52] as well, which has been described above.

\subsection{Load carrying capacity of CCFT columns}

The in-place concrete strength is generally lower than the compressive strength of concrete cylinders $[1,53]$. This difference is mainly attributed to the size effect, shape, and concrete casting quality. A reduction factor of 0.85 is suggested for steel RC columns by ACI 318-11 [53]. A similar reduction factor is suggested for FRP wrapped concrete columns by ACI 440.2R-08 [1] and for FRP bars reinforced concrete columns by Afifi et al. $[55,56]$. Therefore, a reduction factor of 0.85 is used to consider the strength reduction of in-place concrete in this study. The load carrying capacity of CCFT column can be calculated as the sum of axial loads carried by FRP tube, inner concrete, outer confined concrete, and concrete cover:

$$
P=P_{\text {tube }}+P_{i c}+P_{o c}+P_{\text {cover }}=\sigma_{l} A_{f}+0.85 \sigma_{i c} A_{i c}+0.85 \sigma_{o c} A_{o c}+0.85 \sigma_{\text {cover }} A_{\text {cover }}
$$

where $P_{\text {tube }}, P_{i c}, P_{o c}$ and $P_{\text {cover }}$ are the axial loads carried by FRP tube, inner concrete, outer confined concrete, and concrete cover, respectively. $\sigma_{l}, \sigma_{i c}, \sigma_{o c}$ and $\sigma_{c o v e r}$ are the axial compressive strengths of FRP tube, inner concrete, outer confined concrete, and outer unconfined concrete, respectively. $A_{f}$, $A_{i c}, A_{o c}$ and $A_{c o v e r}$ are their corresponding cross-section areas. 
The comparisons between experimental and analytical results are shown in Fig. 7. It can be seen that the analytical results matched well with the experimental results. The analytical model overestimates the first peak loads of CCFT columns, which was mainly attributed to the premature spalling of concrete cover before the unconfined concrete strength was reached. In general, the analytical model predicts the axial load-axial strain behaviour of CCFT columns with good accuracy due to the selection of appropriate stress-strain models for different components of CCFT columns.

Fig. 8 shows the analytical axial load-axial strain curves of Column CCFT-1A(2). The axial load carried by each component is shown as well. At the first stage (before Point A), nearly linear elastic behaviour can be observed for all components. At the second stage (Point A to Point B), the concrete cover began to spall off, which resulted in the loss of axial load. The strength of outer confined concrete was decreased with the increase of axial strain, although the decrease was much less than that of concrete cover. In contrast, the strength of inner concrete was increased due to the confinement provided by the FRP tube, and the axial load carried by FRP tube also showed a linear increase with axial strain. The load reduction of outer concrete was higher than the load increase of inner concrete and FRP tube, which resulted in the overall decrease of axial load. At the third stage (Point B to Point C), with the increase of axial strain, the load increase of inner concrete and FRP tube became larger than the load reduction of outer concrete, which resulted in an overall increase of axial load until the rupture of GFRP tube (Point C). It is noted that the inner concrete-filled FRP tube carried a clear majority of the axial load of the column, and this proportion was even higher with the increase of axial strain. Considering a more ductile failure mode of CCFT columns, it is important that the outer concrete carry some axial load before failure. Under this condition, even though the inner concretefilled FRP tube lost all the strength after the sudden failure, the outer concrete component could still carry significant amount of axial load, which is essential to prevent the overall collapse of the columns [57]. To achieve this, the size of outer concrete can be increased and more confinement as well as additional longitudinal reinforcement can be applied for the outer concrete. 


\section{5. Parametric analyses}

433 Parametric analyses have been carried out to investigate the influences of different parameters on the 434 axial compressive behaviour of CCFT columns. The influences of outer concrete strength, inner concrete strength, FRP tube thickness, filament winding angles of FRP tube, and amount of polymer grid have been analytically investigated. Equation (20) has been used to calculate the axial load capacity of the columns. It is noted that Column CCFT-1A has been used as a reference column. All the parameters in the following analysis have been kept the same as the parameters in Column CCFT$1 \mathrm{~A}$, if not otherwise specified.

\subsection{Influence of inner concrete strength}

Four inner concrete strength grades have been considered (35 MPa, $45 \mathrm{MPa}, 55 \mathrm{MPa}$, and $65 \mathrm{MPa}$ ).

The outer concrete strength is $35 \mathrm{MPa}$, and the FRP tube thickness is $4 \mathrm{~mm}$. All other parameters have been kept constant. Fig. 9 shows the axial load-axial strain behaviour of CCFT columns with different inner concrete strengths. It is evident that the increase in the inner concrete strength can lead to significant increases in both the first peak load and ultimate load. The ultimate axial strain is not significantly influenced by the inner concrete strength, as the failure of concrete columns is dominated by the rupture of GFRP tube.

5.2. Influence of outer concrete strength

451 The influence of outer concrete strength on the axial compressive behaviour of CCFT columns has 452 been investigated using four different concrete strength grades (35 MPa, $45 \mathrm{MPa}, 55 \mathrm{MPa}$, and 65 $\mathrm{MPa}$ ). The inner concrete strength is $35 \mathrm{MPa}$. The FRP tube thickness is $4 \mathrm{~mm}$. All other parameters have been kept constant. The axial load-axial strain behaviours of CCFT columns with different outer concrete strength grades are shown in Fig. 10. It is evident that by increasing the strength of outer concrete, the first peak load can be significantly increased. However, the increase in the ultimate load 
and ultimate axial strain is insignificant. This insignificant effect is mainly because that the outer concrete loses almost all the strength before the failure of concrete columns since the confinement provided by the polymer grid is very low.

\subsection{Influence of FRP tube thickness}

The influence of FRP tube thickness on the axial compressive behaviour of CCFT columns has been investigated by changing the thickness of FRP tubes $(3 \mathrm{~mm}, 4 \mathrm{~mm}, 5 \mathrm{~mm}$, and $6 \mathrm{~mm})$, while all other parameters have been kept constant. The axial load-axial strain behaviour of CCFT columns with different FRP tube thickness is shown in Fig. 11. By increasing the thickness of FRP tube, the first peak load is increased slightly. However, the ultimate load is increased significantly. The increase of axial load is higher with the increase of axial strain especially after the first peak load. This can be explained that due to the linear properties of FRP tube, the axial load carried by the FRP tube increases linearly until failure. Therefore, the axial load difference for FRP tubes with different thicknesses becomes larger with the increase of axial strain.

\subsection{Influence of filament winding angle of FRP tube}

The influence of filament winding angles on the axial compressive behaviour of CCFT columns has been investigated by changing the filament winding angles of FRP tubes. Four different filament winding angles have been selected $\left( \pm 0^{\circ}, \pm 30^{\circ}, \pm 60^{\circ}\right.$, and $\left.\pm 90^{\circ}\right)$. It is noted that the angles are measured with respect to the longitudinal axis of the FRP tubes. The FRP tube thickness is considered $4 \mathrm{~mm}$. All the other parameters have been kept constant. To determine the mechanical properties of FRP tube with different filament winding angles, the software "The laminator" [58] has been used. The Laminator was developed based on the classical laminate theory and provides a reasonable agreement with the test results $[59,60]$. The Tsai-Wu failure criterion has been used to predict the failure of FRP tube, as explained in Section 4.1. 
The axial load-axial strain behaviour of CCFT columns with FRP tubes having different filament 483 winding angles is shown in Fig. 12. CCFT column with FRP tube having all the fibres in the 484 longitudinal direction $\left( \pm 0^{\circ}\right)$ can achieve the highest first peak load and ultimate load, although the ultimate axial strain is the lowest. With the increase of fibres in the transverse direction $\left( \pm 30^{\circ}\right)$, the first peak load is decreased, and the ultimate axial strain is increased. For CCFT columns with FRP tubes having majority of fibres in the longitudinal direction $\left( \pm 0^{\circ}, \pm 30^{\circ}\right)$, the transverse tensile strength is relatively low and a transverse tensile rupture occurs. Therefore, the longitudinal compressive strength of FRP tube cannot be not fully utilized. However, for FRP tubes with majority of fibres along the transverse direction, longitudinal compressive rupture occurs before the transverse tensile strength of FRP tube can be fully utilized $\left( \pm 60^{\circ}, \pm 90^{\circ}\right)$ since the longitudinal compressive strength of the FRP tube is relatively low. Therefore, an optimum proportion of fibres in both longitudinal and transverse direction of FRP tube will significantly improve the performance of CCFT columns under axial compression. It is also noted that the ultimate loads are higher for CCFT columns having FRP tube with majority of fibres aligned in the longitudinal direction $\left( \pm 0^{\circ}, \pm 30^{\circ}\right)$. This can be explained that for concrete confined by very thick FRP tubes, the contribution of axial load by the FPR tube is more significant than the gain from the confinement of concrete. Similar observation has also been reported by Wang et al. [61] and Fam et al. [62].

5.5. Influence of amount of polymer grid

501 The influence of the amount of polymer grid has been investigated by changing the number of polymer grid layers (1 layer, 2 layers, 3 layers, and 4 layers). The strength of both inner and outer concrete is $35 \mathrm{MPa}$. The FRP tube thickness is $4 \mathrm{~mm}$. All other parameters have been kept constant. It can be seen from Fig. 13 that by increasing the amount of polymer grid, the first peak load and ultimate load can be increased only slightly. This is due to the low confinement provided by the polymer grid. Even though the first peak load, ultimate axial load, and ultimate axial strain have not been increased, it is still necessary to apply more amount of polymer grid because the polymer grid 
can be effective in preventing the overall collapse of the concrete columns when the tensile rupture strain of polymer grid is sufficiently high (e.g., Type A polymer grid) [57].

\section{Conclusions}

In this study, the axial compressive behaviour of newly proposed concrete-encased concrete-filled FRP tube (CCFT) stub columns has been experimentally investigated. An analytical model for the prediction of axial load-axial strain behaviour of CCFT columns has been developed and validated with experimental results. Moreover, parametric analyses have been carried out to investigate the influences of different parameters on the axial compressive behaviour CCFT columns. The following conclusions can be drawn:

All CCFT columns in this study obtain considerable amount of strength and ductility under axial compression. The FRP tube provides confinement to the inner concrete and carries axial load. The polymer grid provides confinement to the outer concrete, and the load carrying capacity of CCFT column can be slightly increased by increasing the amount of polymer grid. After the spalling of the concrete cover, the CCFT columns could still carry substantial amount of axial load with a higher axial deformation, which is beneficial for the safe design of concrete columns.

An analytical model is developed to predict the behaviour of CCFT columns under axial compression. The accuracy of the analytical model is validated by comparing the predicted results with the experimental results. The predicted results are found to be in good agreement with the experimental results.

The parametric analyses show that by increasing the inner and outer concrete strength, the first peak load of CCFT column can be increased. The ultimate axial load can be significantly increased by increasing the inner concrete compressive strength. The FRP tube thickness and the filament winding angles significantly influence the ultimate load and ultimate axial strain of CCFT column. The polymer grid does not significantly influence the axial compressive behaviour of CCFT columns, 
533 since the confinement provided by the polymer grid is weak due to the large grid openings and lower

534 tensile properties (tensile strength and tensile elastic modulus).

535 The conclusions in this paper are based on the experimental investigations of 16 concrete stub

536 columns. Therefore, more experiments need to be conducted to fully validate the observed behaviour

537 of CCFT columns. Moreover, the behaviour of CCFT columns under different loading conditions,

538 such as flexural loading and combined axial and lateral loadings should be further investigated before

539 they can be considered as a suitable option in practical applications.

\section{Acknowledgments}

542 The authors gratefully acknowledge the contributions of Messrs Jiansong Yuan, Ritchie Mclean, Alan

543 Grant and Fernando Escribano for their help in carrying out the experiments. The authors also thank

544 Wagners CFT for providing GFRP tubes. The first author acknowledges the China Scholarship

545 Council and the University of Wollongong, Australia, for supporting his PhD scholarship.

\section{$548 \quad$ Notation}

$A_{f} \quad=$ cross-section area of FRP tube;

$A_{g} \quad=$ cross-section area of polymer grid;

$A_{i c} \quad=$ cross-section area of inner concrete;

$A_{o c}=$ cross-section area of outer confined concrete;

$b_{g} \quad=$ width of polymer grid;

$C_{j}=$ confinement modulus;

$d_{g} \quad=$ diameter of polymer grid;

$E_{2}=$ slope of the linear second portion of the stress-strain curve of inner

confined concrete;

$E_{c} \quad=$ elastic modulus of unconfined concrete; 


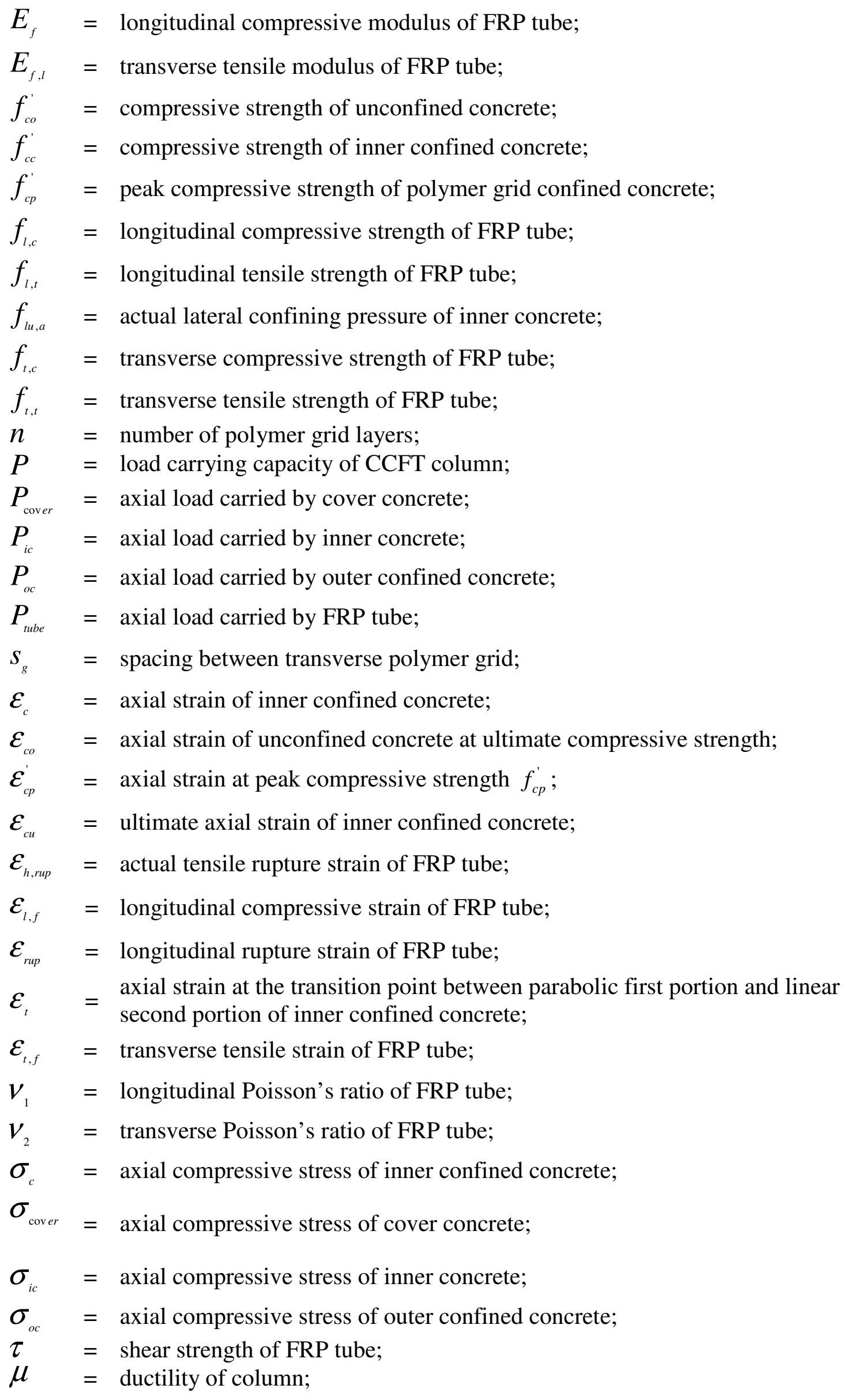


$\delta_{y} \quad=$ axial deformation at yield load; and

549

$\delta_{u} \quad=$ axial deformation at ultimate load.

\section{References}

551 [1] ACI 440.2R-08. Guide for the design and construction of externally bonded FRP systems for

552 strengthening concrete structures. American Concrete Institute, Farmington Hills, Michigan, USA; 5532008.

554 [2] Lam L, Teng JG. Design-oriented stress-strain model for FRP-confined concrete. Construction and 555 Building Materials 2003; 17(6-7): 471-489.

556 [3] Hadi MNS. Behaviour of FRP strengthened concrete columns under eccentric compression loading. Composite Structures 2007; 77(1): 92-96.

[4] Mirmiran A, Shahawy M. Behaviour of concrete columns confined by fiber composites. Journal of Structural Engineering 1997, 123(5): 583-590.

560 [5] Fam A, Rizkalla S. Behaviour of axially loaded concrete-filled circular fibre-reinforced polymer 561 tubes. ACI Structural Journal 2001; 98(3): 280-289.

562 [6] Fam A, Rizkalla S. Flexural behaviour of concrete-filled fibre reinforced polymer circular tubes. 563 Journal of Composites for Construction 2002; 6(2):123-132.

564 [7] Ozbakkaloglu T. Compressive behaviour of concrete-filled FRP tube columns: Assessment of 565 critical column parameters. Engineering Structures 2013; 51: 188-199.

566 [8] Chen L, Ozbakkaloglu T. Corner strengthening of square and rectangular concrete-filled FRP 567 tubes. Engineering Structures 2016; 117: 486-495.

568 [9] Vincent T, Ozbakkaloglu T. Influence of shrinkage on compressive behavior of concrete-filled 569 FRP tubes: An experimental study on interface gap effect. Construction and Building Materials 2015; 75: $144-156$. 
571 [10] Vincent T, Ozbakkaloglu T. Influence of slenderness on stress-strain behavior of concrete-filled

572 FRP tubes: an experimental study. Journal of Composites for Construction 2015; 19: 04014029-1-13.

573 [11] GB-50608. Technical code for infrastructure application of FRP composites. China planning 574 press 2010, China.

575 [12] Ji G, Li G, Li X, Pang S, Jones R. Experimental study of FRP tube encased concrete cylinders 576 exposed to fire. Composite Structures 2008; 85(2):149-154.

577 [13] Ji, G., G. Li, and W. Alaywan, A new fire resistant FRP for externally bonded concrete repair. 578 Construction and Building Materials, 2013. 42: p. 87-96.

579 [14] Dai JG, Bai YL, Teng JG. Behavior and modeling of concrete confined with FRP composites of 580 large deformability. Journal of Composites for Construction. 2011;15(6):963-73.

581 [15] Sadeghian P, Lai Y, Fam A. Testing and modeling of a new moment connection of concrete582 filled FRP tubes to footings under monotonic and cyclic loadings. Journal of Composites for 583 Construction 2011; 15(4): 653-662.

584 [16] ACI 440.1R. Guide for the design and construction of structural concrete reinforced with FRP 585 bars. USA: American Concrete Institute, Farmington Hills; 2006.

586 [17] Benmokrane B, Chaallal O, Masmoudi R. Flexural response of concrete beams reinforced with 587 FRP reinforcing bars. ACI Structural Journal 1996; 93(1):46-55.

588

[18] Yost JR, Gross SP, Dinehart DW. Shear strength of normal strength concrete beams reinforced 589 with deformed GFRP bars. Journal of Composites for Construction 2001; 5(4):268-275.

590 [19] Mallick PK. Fibre reinforced composites, materials, manufacturing, and design. New York, $591 \quad$ Marcell Dekker; 1988.

592 [20] Nanni A, Rizkalla S, Bakis C, Conrad JO, Abdelrahman A. Characterization of GFRP ribbed rod 
593

594

595

596

597

598

599

600

601

602

603

604

605

606

607

608

609

610

611

612

613

614

615

used for reinforced concrete construction. In: Proceedings of the International Composites Exhibition; 1998:11-16.

[21] De Luca A, Matta F, Nanni A. Behaviour of full-scale glass fibre-reinforced polymer bars reinforced concrete columns under axial load. ACI Structural Journal 2010;107(5):589-596.

[22] Mohamed H, Afifi M, and Benmokrane B. Performance evaluation of concrete columns reinforced longitudinally with FRP bars and confined with FRP hoops and spirals under axial load. Journal of Bridge Engineering, 2014. 19(7): 0401402.

[23] Hadi MNS., Karim H, and Sheikh MN. Experimental Investigations on Circular Concrete Columns Reinforced with GFRP Bars and Helices under Different Loading Conditions. Journal of Composites for Construction, 2016. 20(4): 04016009.

[24] Hadi MNS, Zhao H. Experimental Study of High-Strength Concrete Columns Confined with Different Types of Mesh under Eccentric and Concentric Loads. Journal of Materials in Civil Engineering 2011, 23(6): 823-832.

[25] Wang W, Sheikh MN, Hadi MNS. Axial compressive behaviour of concrete confined with polymer grid. Materials and Structures/Materiaux et Constructions 2016, 49:3893-3908.

[26] Nie J, Bai Y, Cai CS. New connection system for confined concrete columns and beams. I: Experimental study. Journal of Structural Engineering 2008,134:1787-1799.

[27] Wagners: Composite Fibre Technologies. 339 Anzac Avenue, Toowoomba, QLD Australia. http://www.wagnerscft.com.au/ (Accessed on June 2015).

[28] Polyfabrics Australia Pty Ltd. 5 Frost Road, Campbelltown, Sydney, NSW Australia. http://www.polyfabrics.com.au/index-2.html/ (Accessed on June 2015).

[29] Maccaferri Australia Pty Ltd. 22 Powers Road, Seven Hills, Sydney, NSW Australia. http://www.maccaferri.com.au/afawcs0137304/Home.html/ (Accessed on June 2015). 
616 [30] Nanjing Hitech Composites Co.,Ltd. Dongping Industrial Park, Lishui, Nanjing, Jiangsu

617 Province, China. http://www.hitechfrp.com/haituo/indexyw.asp/(Accessed on June 2015)

618 [31] BASF Australia, 11 Stanton Rd, Seven Hills, NSW, Australia. https://www.master-builders619 solutions.basf.com.au/en-au/products/ (Accessed on March 2017)

620 [32] ASTM D7565/D7565M-10. Standard test method for determining tensile properties of fibre 621 reinforced polymer matrix composites used for strengthening of civil structures. United States: ASTM International; 2010.

623

[33] GB/T 5350-05. Test method for longitudinal compressive properties of fiber-reinforced 624 thermosetting plastic pipe. China: 2005.

[34] Wang W, Sheikh MN, Hadi MNS. Behaviour of perforated GFRP tubes under axial compression. Thin-Walled Structures 2015,95:88-100.

627 [35] Hadi MNS, Wang W, Sheikh MN. Axial compressive behaviour of GFRP tube reinforced 628 concrete columns. Construction and Building Materials 2015; 81:198-207.

[36] Karim H, Sheikh MN, Hadi MNS. Axial load-axial deformation behaviour of circular concrete 630 columns reinforced with GFRP bars and helices. Construction and Building Materials, 2016, $631 \quad 112: 1147-57$.

[37] Gunes O, Lau D, Tuakta C, Büyüköztürk O. Ductility of FRP-concrete systems: Investigations at different length scales. Construction and Building Materials, 2013, 49:915-925.

634

[38] Teng JG, Lam L. Behaviour and modelling of FRP-confined concrete. Journal of Structural 635 Engineering, 2004, 130(11):1713-1723.

636

[39] Lim JC, Ozbakkaloglu T. Lateral strain-to-axial strain relationship of confined concrete. Journal 637 of Structural Engineering. 2015;141(5):04014141. 
[40] Lim JC, Ozbakkaloglu T. Investigation of the influence of the application path of confining pressure: Tests on actively confined and FRP-confined concretes. Journal of Structural Engineering. 2015;141(8):04014203.

[41] Lim JC, Ozbakkaloglu T. Hoop strains in FRP-confined concrete columns: experimental observations. Materials and Structures/Materiaux et Constructions. 2015;48(9):2839-54.

[42] Chen J, Li S, Bisby L. Factors affecting the ultimate condition of FRP-wrapped concrete columns. Journal of Composites for Construction 2013; 17 (1): 67-78.

[43] Bank LC. Composites for construction: Structural design with FRP materials. Hoboken, New Jersey: John Wiley \& Sons; 2006.

[44] Tsai SW. Strength theories of filamentary structures in fundamental aspects of fiber reinforced plastic composites. Schwartz RT, Schwartz HS, Eds., Wiley Interscience, New York 1968.

[45] Tsai SW, Wu EM. A general theory of strength for anisotropic materials. Journal of Composite Materials 1971; 5:58-80.

[46] Tsai SW. A survey for macroscopic failure criteria for composite materials. Journal of Reinforced Plastics and Composites 1984; 3:40-62.

[47] Hinton MJ, Kaddour AS, Soden PD. Evaluation of failure prediction in composite laminates: background to 'part B' of the exercise. Composites Science and Technology 2002,62:1481-1488.

[48] Ozbakkaloglu T, Lim JC, Vincent T. FRP-confined concrete in circular sections: review and assessment of stress-strain models. Engineering Structures 2013; 49: 1068-1088.

[49] Michael AP, Hamilton III HR, Ansley MH. Concrete confinement using carbon fibre reinforced polymer grid. ACI Special Publication 2005; 230: 991-1010.

[50] Lim JC, Ozbakkaloglu T. Unified stress-strain model for FRP and actively confined normalstrength and high-strength concrete. Journal of Composites for Construction. 2015;19(4):04014072. 
661 [51] Lim JC, Ozbakkaloglu T. Stress-strain model for normal- and light-weight concretes under 662 uniaxial and triaxial compression. Construction and Building Materials. 2014;71:492-509.

663 [52] Mander JB, Priestley MJN, Park R. Theoretical stress-strain model for confined concrete. 664 Journal of Structural Engineering 1988; 114(8):1804-1826.

665 [53] ACI committee 318. Building code requirements for structural concrete (ACI 318-11) and 666 commentary. Farmington Hills, MI: ACI American Concrete Institute; 2011.

[54] Sheikh, S. A., Uzumeri, S. M. Analytical model for concrete confinement in tied columns. Journal of the Structural Division 1982; 108(12): 2703-2722.

[55] Afifi M, Mohamed H, Benmokrane B. Strength and axial behavior of circular concrete columns reinforced with CFRP bars and spirals. Journal of Composites for Construction 2014;18(2), 04013035.

671 [56] Afifi M, Mohamed H, Benmokrane B. Axial capacity of circular concrete columns reinforced 672 with GFRP bars and spirals. Journal of Composites for Construction 2014;18(1), 04013017.

[57] Feng P, Cheng S, Bai Y, Ye L. Mechanical behavior of concrete-filled square steel tube with FRP-confined concrete core subjected to axial compression. Composite Structures 2015,123:312-324.

[58] The Laminator. Version 3.7. http://www.thelaminator.net/ (Accessed on June 2015).

[59] Mohamed H, Masmoudi R. Axial load capacity of concrete-filled FRP tube columns: experimental versus theoretical predictions. Journal of Composites for Construction 2010;14(2), 231243.

[60] Vincent T, Ozbakkaloglu T. Influence of fiber orientation and specimen end condition on axial compressive behavior of FRP-confined concrete. Construction and Building Materials. 2013;47:81426.

[61] Wang W, Sheikh MN, Hadi MNS. Experimental study on FRP tube reinforced concrete columns under different loading conditions. Journal of Composites for Construction 2016, 20 (5): 04016034. 
684 [62] Fam A, Flisak B, Rizkalla S. Experimental and analytical modelling of concrete-filled fiber685 reinforced polymer tubes subjected to combined bending and axial loads. ACI Structural Journal $686 \quad 2003 ; 100(4): 499-509$. 
688 Table 1. Test matrix

689 Table 2. Mechanical properties of GFRP tubes

690 Table 3. Mix design of concrete

691 Table 4. Summary of test results

692 
694 Fig. 1. Cross-section of concrete-encased concrete-filled FRP tube (CCFT) column

695 Fig. 2. Formwork before casting

696 Fig. 3. Tensile stress-tensile strain behaviour of polymer grid

697 Fig. 4. Failure modes

698 Fig. 5. Axial load -axial deformation behaviour of Groups P(1), FC-1(1), FC-2(1), CCFT-0(1), CCFT-

$6991 \mathrm{~A}(1)$, and CCFT-2A(1) columns

700 Fig. 6. Axial load -axial deformation behaviour of Groups P(1), FC-1(1), FC-2(1), CCFT-0(1), CCFT-

701 1B(1), and CCFT-2B(1) columns

702 Fig. 7. Comparisons between experimental results and model predictions

703 Fig. 8. Load carried by each component of CCFT-1A column

704 Fig. 9. Axial load-axial strain behaviour of columns for different inner concrete strength

705 Fig. 10. Axial load-axial strain behaviour of columns for different outer concrete strength

706 Fig. 11. Axial load-axial strain behaviour of columns for different FRP tube thicknesses

707 Fig. 12. Axial load-axial strain behaviour of columns for different filament winding angles

708 Fig. 13. Axial load-axial strain behaviour of columns for different amount (number of layers) of 709 polymer grid 
Table 1. Test matrix.

\begin{tabular}{lccc}
\hline Specimen & $\begin{array}{c}\text { Inner concrete } \\
\text { confinement }\end{array}$ & Outer concrete confinement & External confinement \\
\hline P & -- & -- & -- \\
FC-1 & -- & -- & 1 layer of CFRP \\
FC-2 & -- & -- & 2 layers of CFRP \\
CCFT-0 & GFRP tube & -- & -- \\
CCFT-1A & GFRP tube & 1 layer of Type A polymer grid & -- \\
CCFT-2A & GFRP tube & 2 layers of Type A polymer grid & -- \\
CCFT-1B & GFRP tube & 1 layer of Type B polymer grid & -- \\
CCFT-2B & GFRP tube & 2 layers of Type B polymer grid & -- \\
\hline
\end{tabular}

711

712

713 
Table 2. Mechanical properties of GFRP tubes.

\begin{tabular}{|c|c|c|c|c|c|c|}
\hline \multicolumn{2}{|c|}{ Ultimate Tensile Strength (MPa) } & \multicolumn{2}{|c|}{ Ultimate Compressive Strength (MPa) } & \multirow{2}{*}{$\begin{array}{l}\text { Shear Strength } \\
\qquad(\mathrm{MPa})\end{array}$} & \multicolumn{2}{|c|}{$\begin{array}{l}\text { Modulus of Elasticity } \\
\qquad(\mathrm{GPa})\end{array}$} \\
\hline Longitudinal & Transverse & Longitudinal & Transverse & & Longitudinal & Transverse \\
\hline 650 & 41 & 550 & 104 & 84 & 35.4 & 12.9 \\
\hline
\end{tabular}

716 
Table 3. Mix design of concrete.

720

\begin{tabular}{lc}
\hline Constituent & Values \\
\hline Cement $\left(\mathrm{kg} / \mathrm{m}^{3}\right)$ & 260 \\
Fly ash $\left(\mathrm{kg} / \mathrm{m}^{3}\right)$ & 100 \\
Coarse aggregate $\left(\mathrm{kg} / \mathrm{m}^{3}\right)$ & 950 \\
Coarse sand $\left(\mathrm{kg} / \mathrm{m}^{3}\right)$ & 532 \\
Fine sand $\left(\mathrm{kg} / \mathrm{m}^{3}\right)$ & 228 \\
Water $\left(\mathrm{kg} / \mathrm{m}^{3}\right)$ & 187 \\
Pozz80 water reducer $\left(\mathrm{mL} / \mathrm{m}^{3}\right)$ & 350 \\
MA940 air entrainer $\left(\mathrm{mL} / \mathrm{m}^{3}\right)$ & 70 \\
\hline
\end{tabular}

721

722 
Table 4. Summary of test results.

\begin{tabular}{|c|c|c|c|c|c|c|c|}
\hline Specimen & $\begin{array}{l}\text { First peak } \\
\text { load }(\mathrm{kN})\end{array}$ & $\begin{array}{c}\text { Axial } \\
\text { deformation at } \\
\text { first peak load } \\
\delta_{y}(\mathrm{~mm})\end{array}$ & $\begin{array}{l}\text { Ultimate } \\
\text { load }(\mathrm{kN})\end{array}$ & $\begin{array}{l}\text { Axial deformation } \\
\text { at ultimate load, } \\
\qquad \delta_{u}(\mathrm{~mm})\end{array}$ & $\begin{array}{l}\text { Axial strain } \\
\text { at ultimate } \\
\text { load }(\%)\end{array}$ & $\begin{array}{l}\text { Hoop strain at the } \\
\text { ultimate load }(\%)\end{array}$ & $\begin{array}{c}\text { Ductility } \\
\mu\end{array}$ \\
\hline $\mathrm{P}(1)$ & 613 & 1.180 & 613 & 1.180 & - & - & 1.000 \\
\hline $\mathrm{P}(2)$ & 614 & 1.178 & 614 & 1.178 & - & - & 1.000 \\
\hline FC-1(1) & 616 & 1.185 & 874 & 5.871 & - & - & 4.954 \\
\hline FC-1(2) & 596 & 1.105 & 829 & 5.844 & - & - & 5.288 \\
\hline FC-2(1) & 688 & 1.421 & 1240 & 9.431 & - & - & 6.637 \\
\hline FC-2(2) & 652 & 1.451 & 1198 & 9.006 & - & - & 6.207 \\
\hline CCFT-0(1) & 583 & 1.410 & 1124 & 13.011 & 1.58 & 1.05 & 9.228 \\
\hline CCFT-0(2) & 590 & 1.170 & 1079 & 12.315 & 1.66 & 1.08 & 10.530 \\
\hline CCFT-1A(1) & 521 & 1.473 & 1159 & 13.412 & 1.61 & 0.86 & 9.105 \\
\hline CCFT-1A(2) & 515 & 1.299 & 1115 & 13.304 & 1.64 & 0.99 & 10.242 \\
\hline CCFT-2A(1) & 535 & 1.527 & 1166 & 12.927 & 1.68 & 0.82 & 8.467 \\
\hline CCFT-2A(2) & 478 & 1.544 & 1195 & 13.346 & - & - & 8.644 \\
\hline CCFT-1B(1) & 492 & 1.381 & 1154 & 13.129 & 1.69 & 0.93 & 9.507 \\
\hline CCFT-1B(2) & 528 & 1.444 & 1134 & 12.599 & 1.55 & 1.00 & 8.725 \\
\hline CCFT-2B(1) & 555 & 1.400 & 1180 & 13.154 & 1.63 & 0.98 & 9.396 \\
\hline CCFT-2B(2) & 502 & 1.128 & 1187 & 12.822 & - & - & 11.367 \\
\hline
\end{tabular}

Note: The number within the bracket specifies the two identical columns used in each group. 


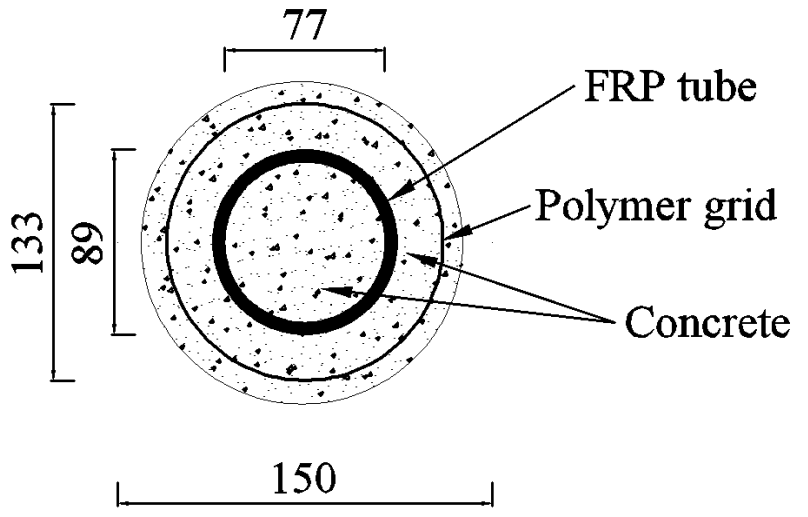

Fig. 1. Cross-section of circular concrete-encased concrete-filled FRP tube (CCFT) column 


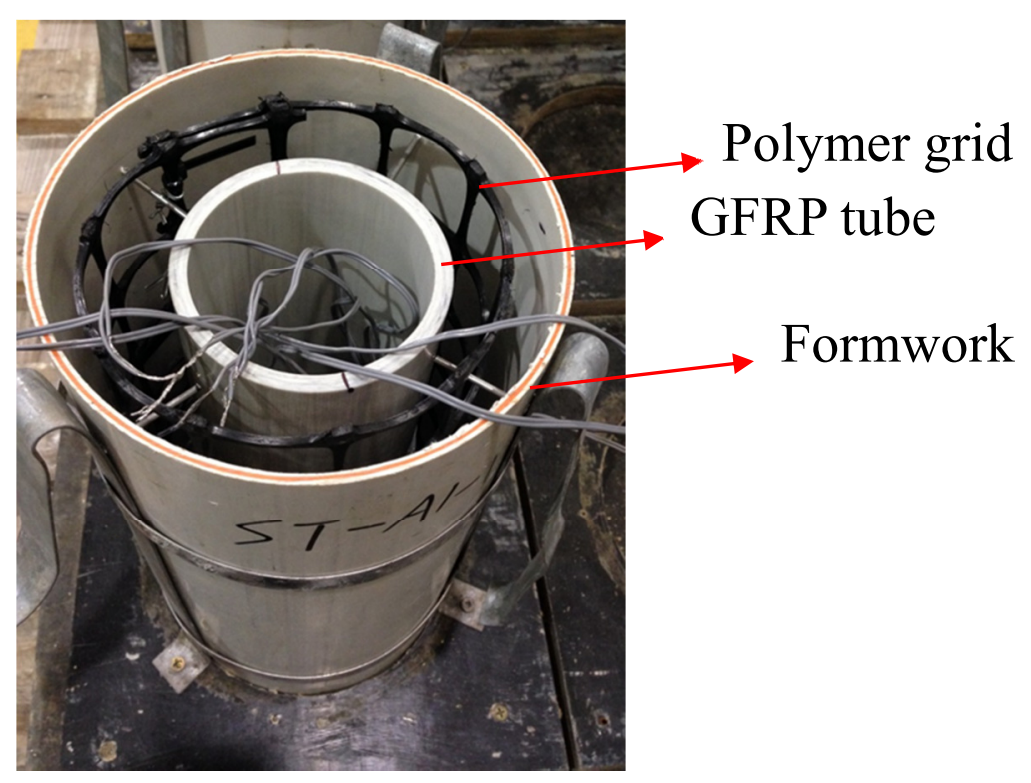

Fig. 2. Formwork before casting 


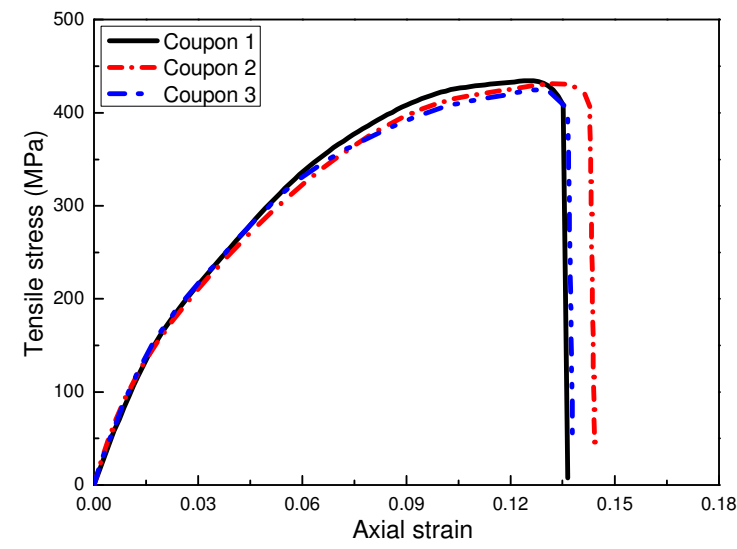

(a) Type A polymer grid

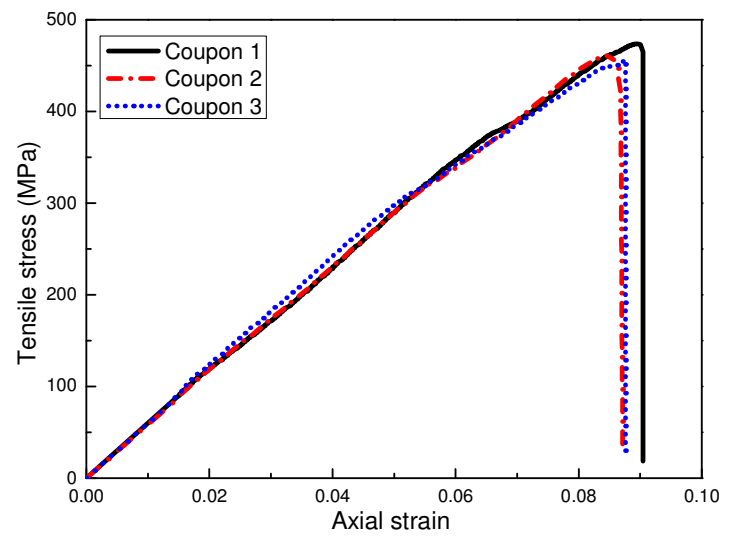

(b) Type B polymer grid

Fig. 3. Tensile stress-tensile strain behaviour of polymer grid 


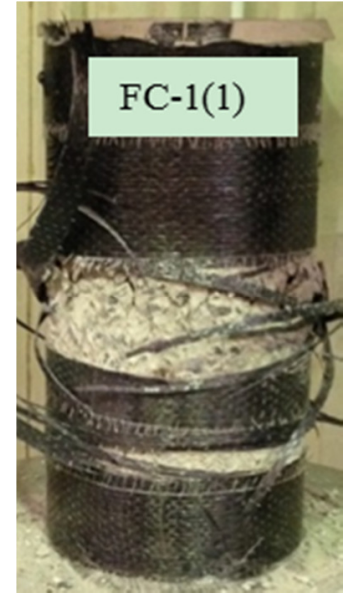

(a) FC-1(1)

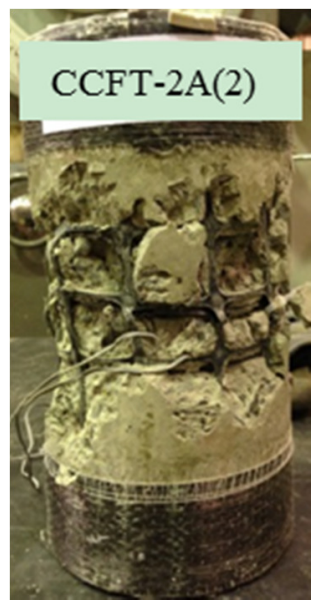

(d) CCFT-2A(2)

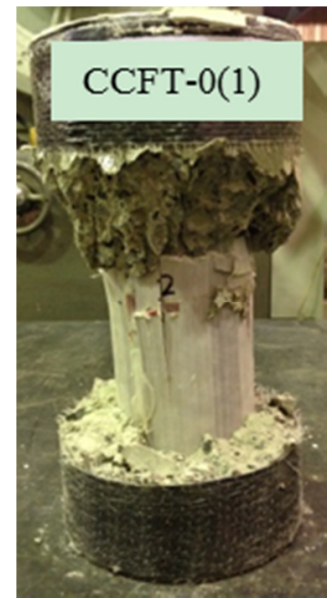

(b) CCFT-0(1)

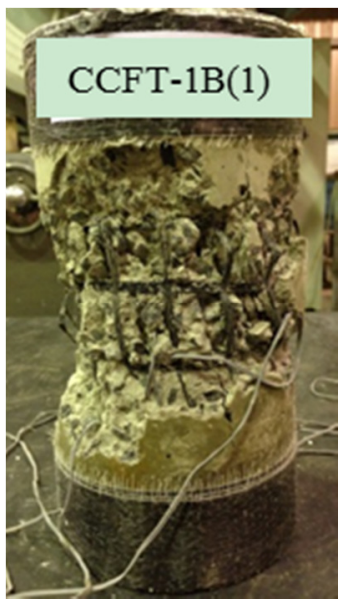

(e) CCFT-1B(1)

Fig. 4. Failure modes

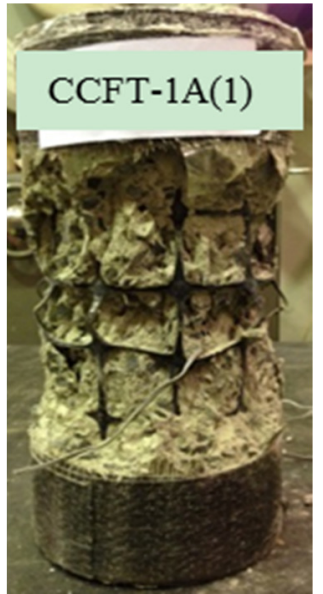

(c) $\mathrm{CCFT}-1 \mathrm{~A}(1)$

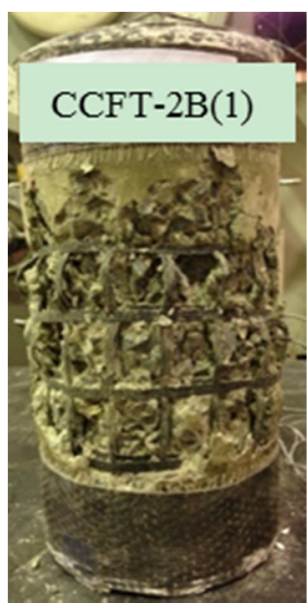

(f) CCFT-2B (1) 


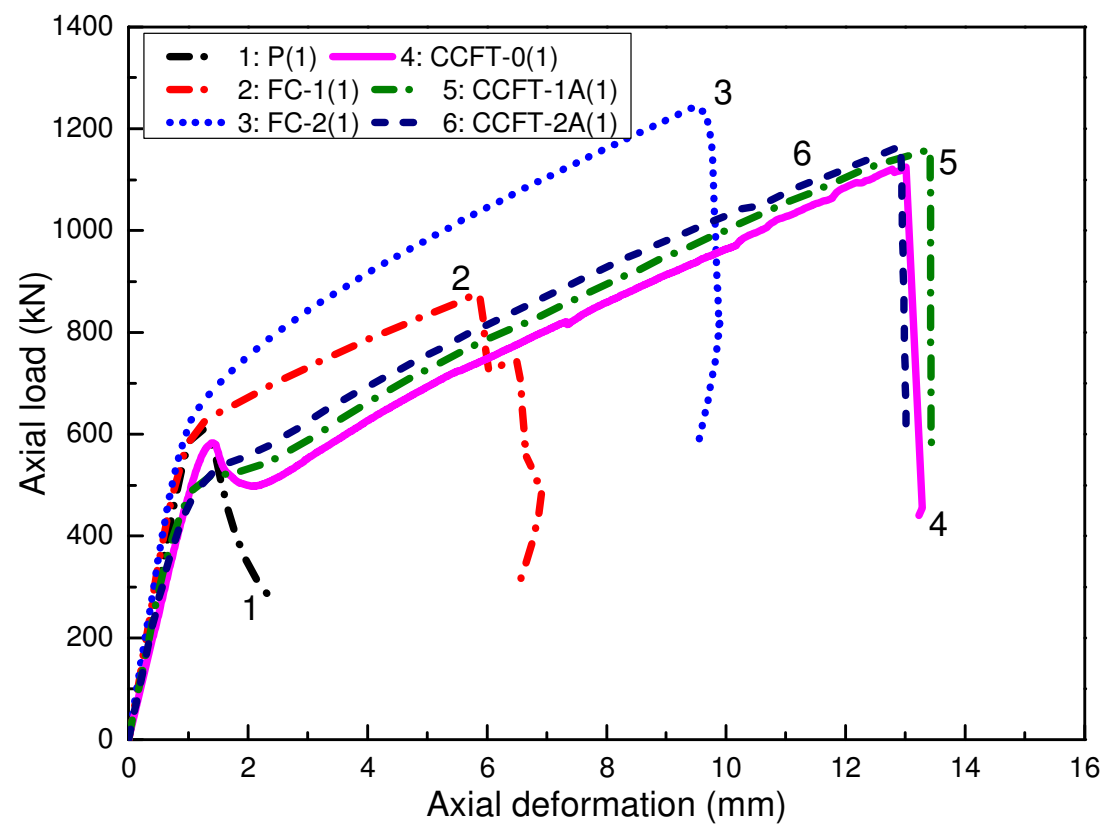

Fig. 5. Axial load -axial deformation behaviour of Groups P(1), FC-1(1), FC-2(1), CCFT-0(1), CCFT$1 \mathrm{~A}(1)$, and CCFT-2A(1) columns 


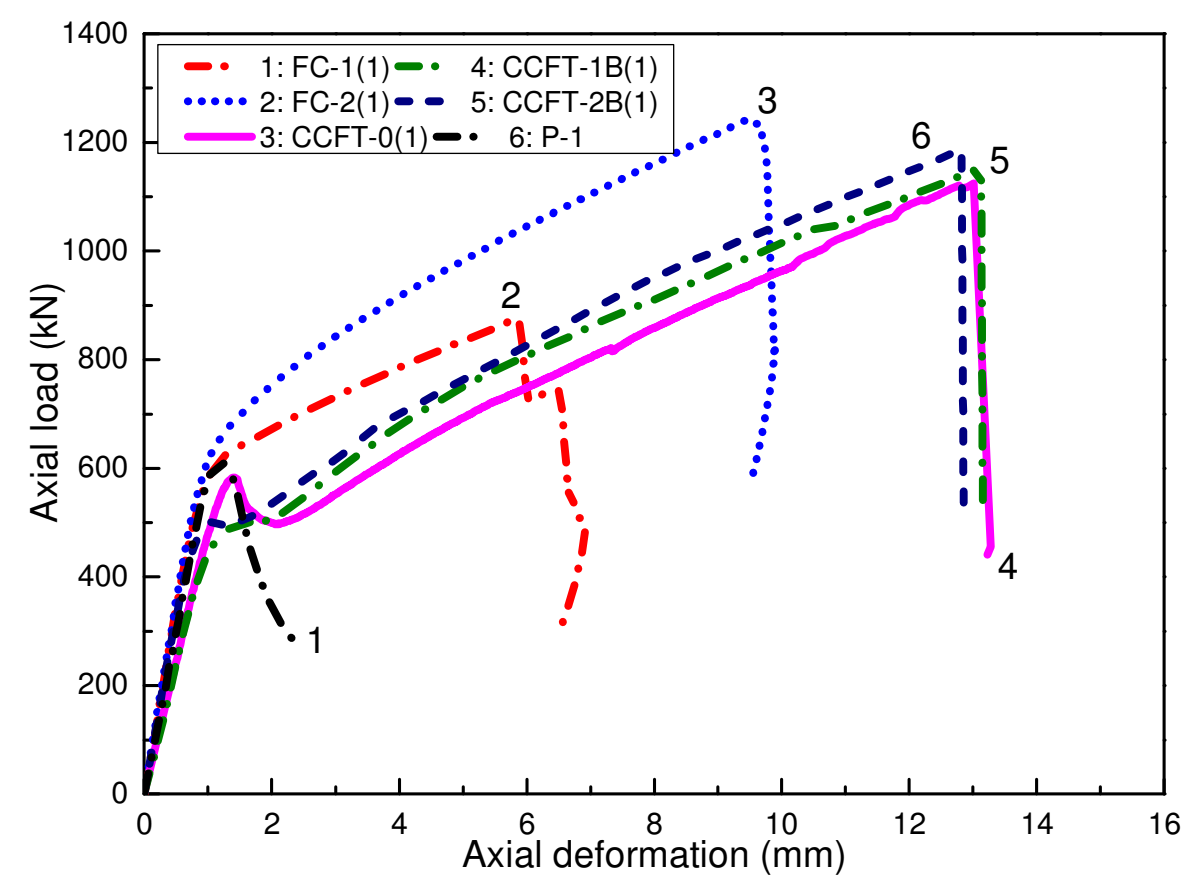

Fig. 6. Axial load -axial deformation behaviour of Groups P(1), FC-1(1), FC-2(1), CCFT-0(1), CCFT1B(1), and CCFT-2B(1) columns 


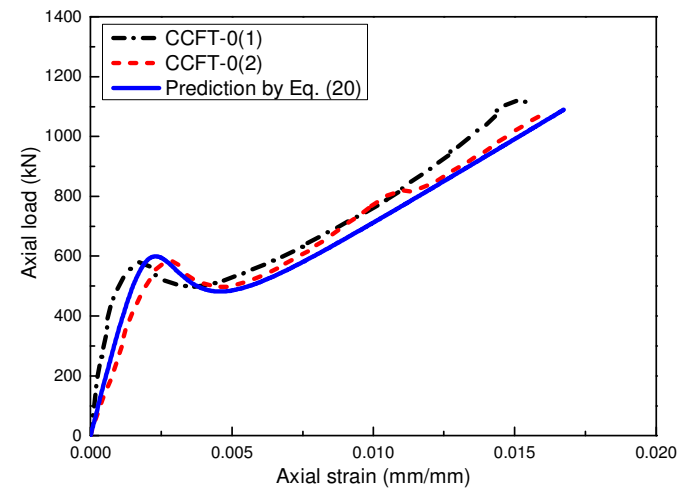

(a) Columns CCFT-0

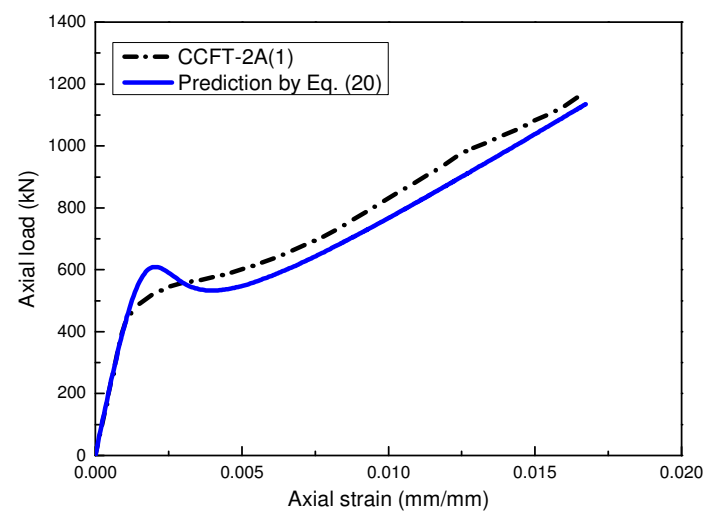

(c) Column CCFT-2A

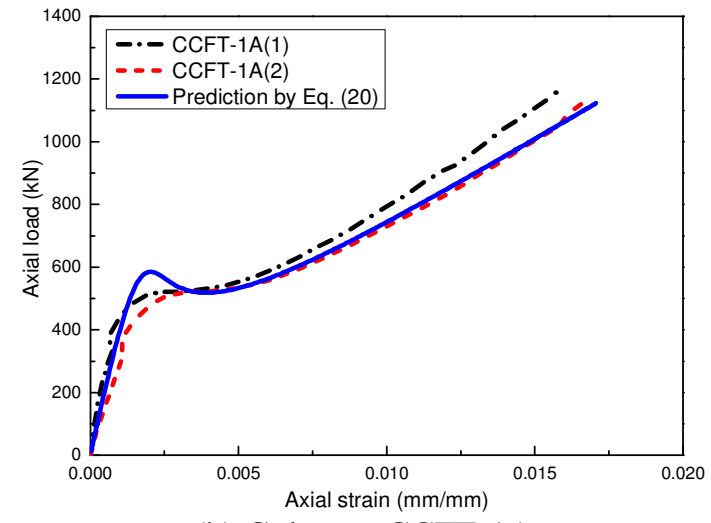

(b) Columns CCFT-1A

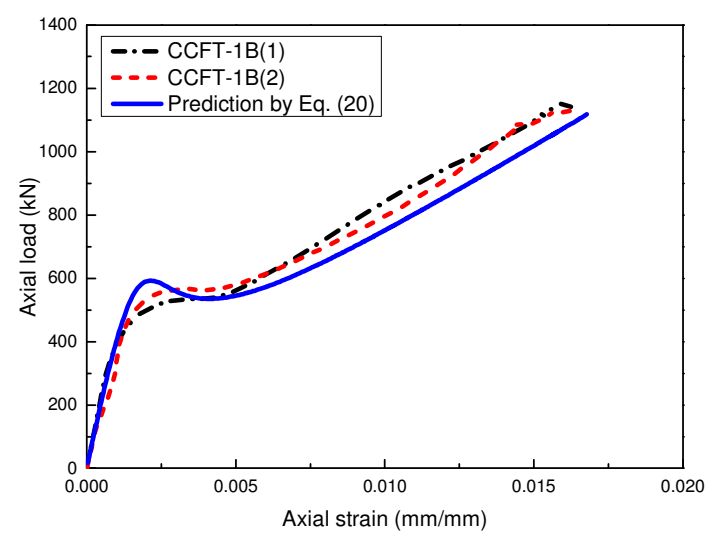

(d) Columns CCFT-1B

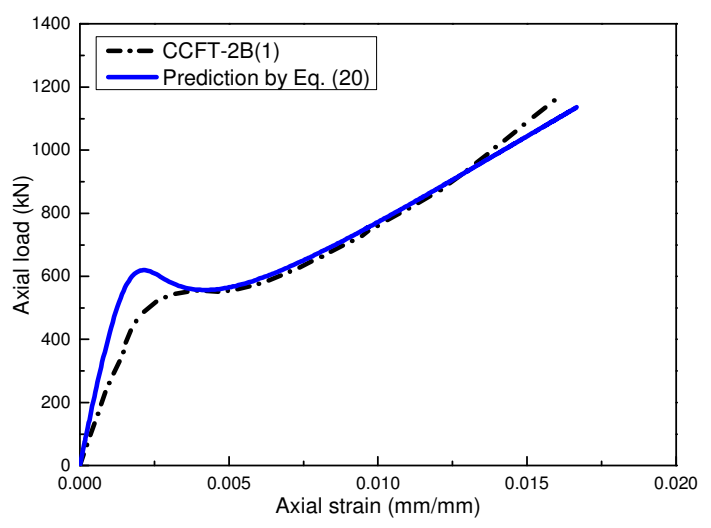

(e) Column CCFT-2B

Fig. 7. Comparisons between experimental results and model predictions (Note: the strain gauges failed during the test for Columns CCFT-2A(2) and CCFT-2B(2)) 


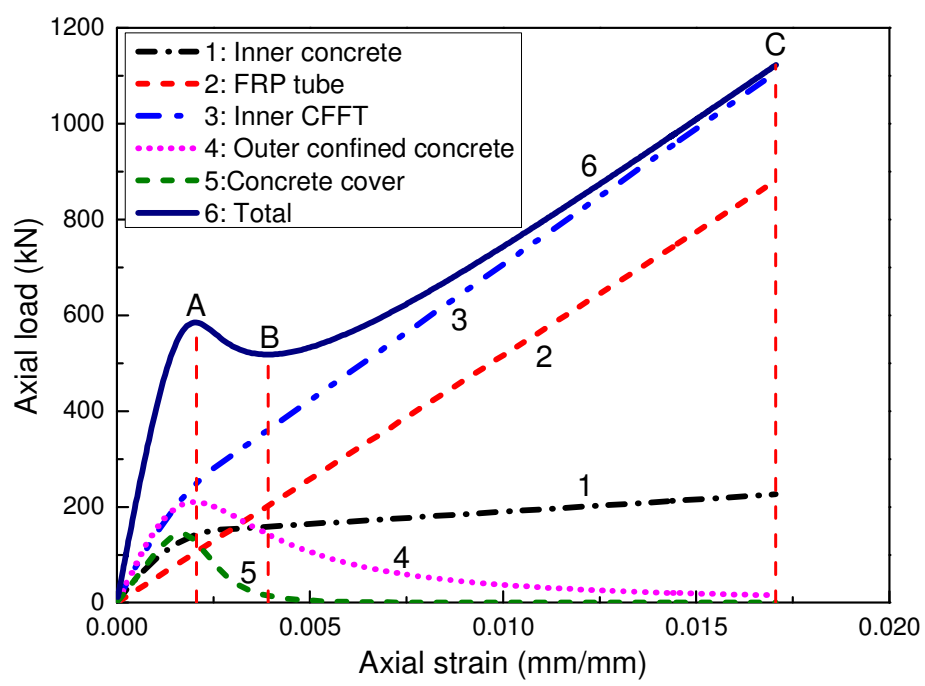

Fig. 8. Load carried by each component of Column CCFT-1A (Note: Eq. (2) was used to calculate the axial stress of FRP tube; Eqs. (5), (6) were used to calculate the axial stress of inner concrete; and Eq. (11) was used to calculate the axial stress of outer confined concrete and concrete cover) 


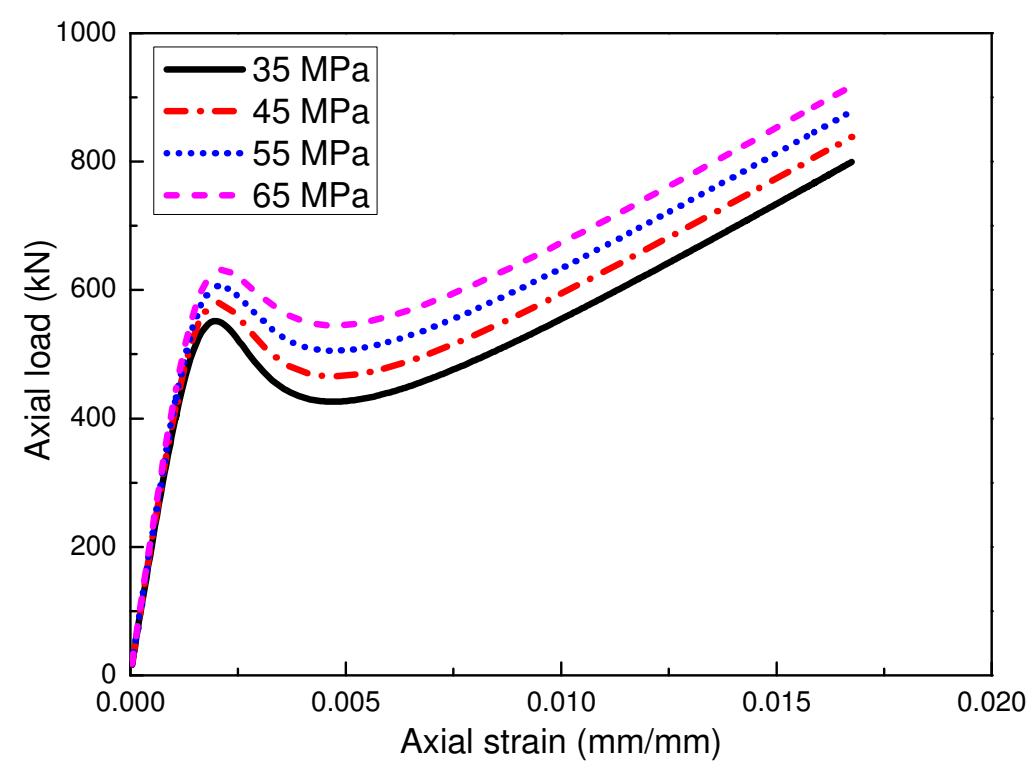

Fig. 9. Axial load-axial strain behaviour of columns for different inner concrete strength 


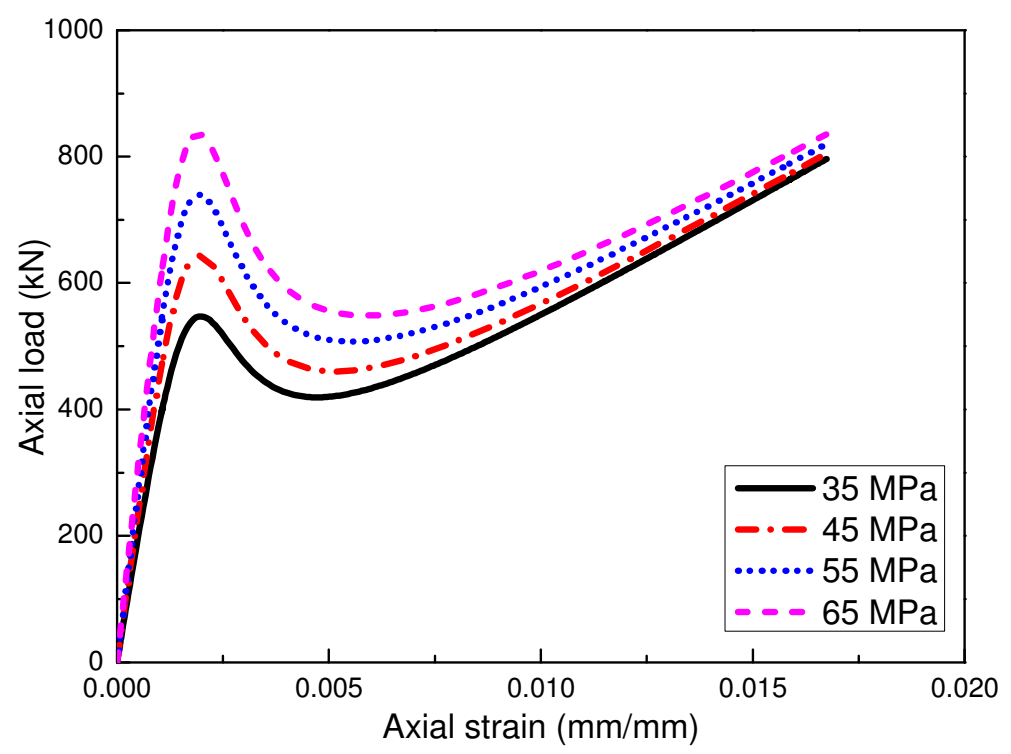

Fig. 10. Axial load-axial strain behaviour of columns for different outer concrete strength 


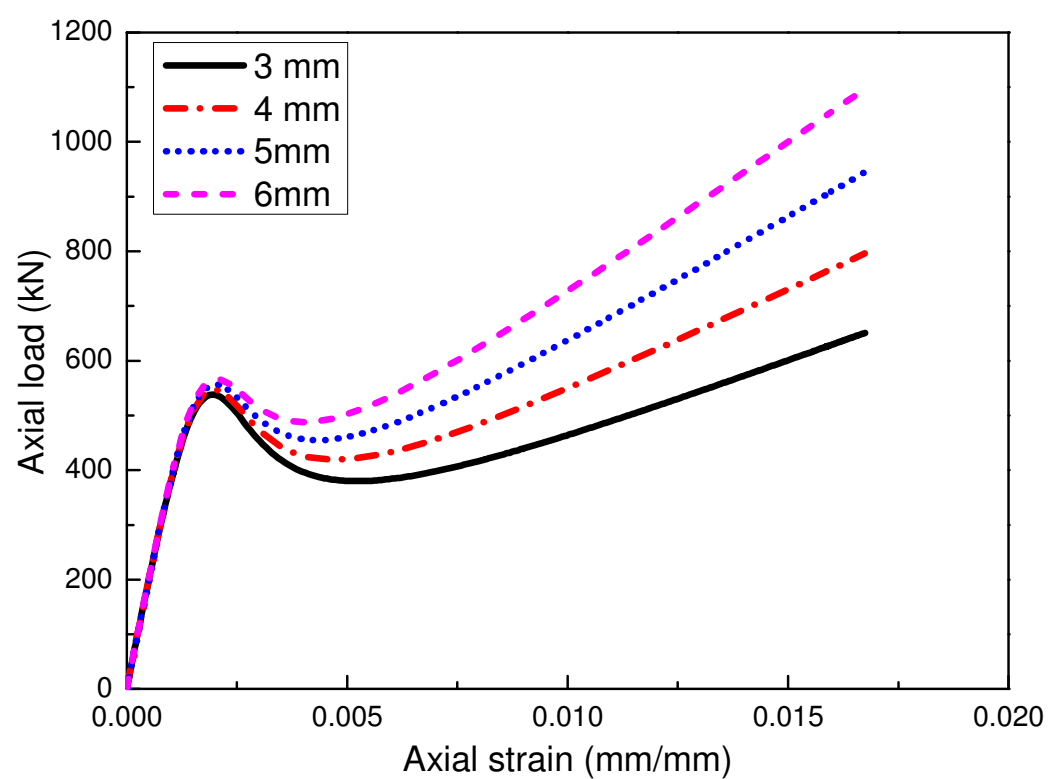

Fig. 11. Axial load-axial strain behaviour of columns for different FRP tube thicknesses 


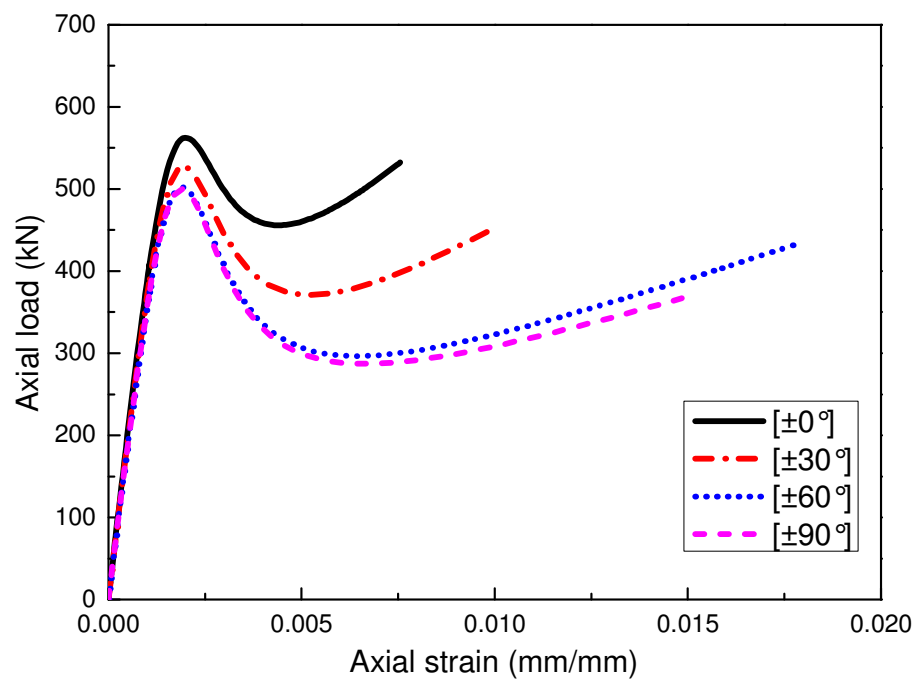

Fig. 12. Axial load-axial strain behaviour of columns for different filament winding angles of FRP tubes 


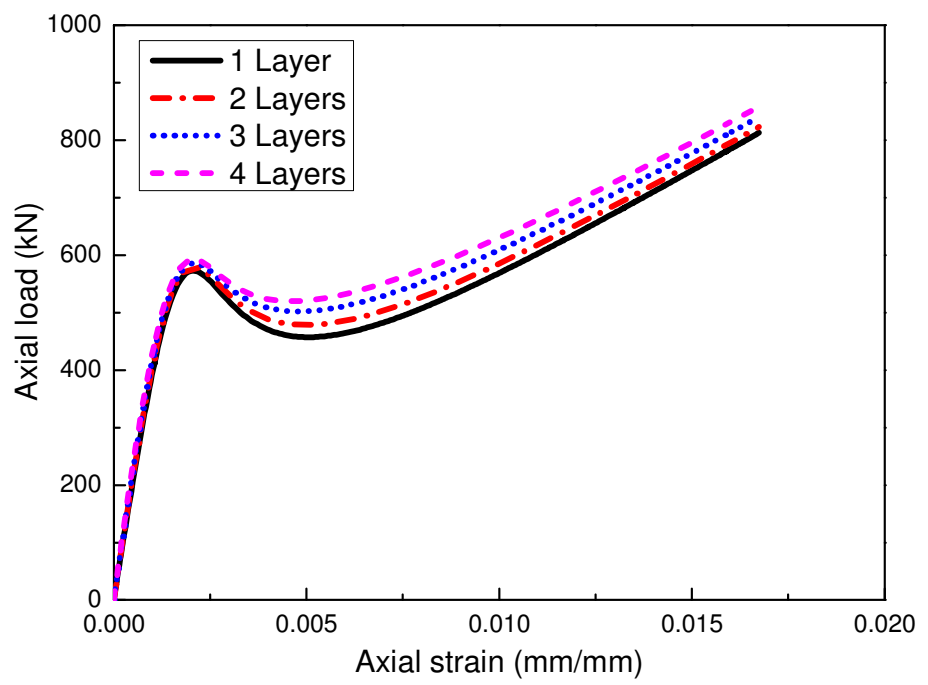

Fig. 13. Axial load-axial strain behaviour of columns for different amount (number of layers) of polymer grid 